\title{
Homework in Monetary Economics: Inflation, Home Production, and the Production of Homes*
}

\author{
S. Borağan Aruoba ${ }^{\dagger}$ \\ University of Maryland
}

Morris A. Davis

University of Wisconsin - Madison

Randall Wright

University of Wisconsin - Madison, FRB Minneapolis, FRB Chicago and NBER

July 14, 2014

\begin{abstract}
We introduce household production and the production of houses (construction) into a monetary model. Theory predicts inflation, as a tax on market activity, encourages substitution into household production and hence investment in housing. In the model, the stock and appropriately-deflated price of housing increase with inflation or nominal interest rates. We document this in data for the U.S. and other countries. A calibrated model accounts for up to $52 \%(87 \%)$ of the relationship between interest rates and housing wealth deflated by nominal output (by the money supply). It also implies the cost of inflation is higher than in models without home production.
\end{abstract}

${ }^{*}$ We thank many friends and colleagues for helpful input, especially Christophe André, Jeff Campbell, Larry Christiano, Marcello Veracierto, Yu Zhu, and Gwen Eudey. Aruoba and Wright also thank the NSF, Davis and Wright thank the Lincoln Institute of Land Policy, and Wright thanks the Ray Zemon Chair in Liquid Assets at the Wisconsin School of Business for research support. The usual disclaimer applies.

${ }^{\dagger}$ Corresponding author. email: aruoba@econ.umd.edu; phone: 301-405-3508. 


\section{Introduction}

This paper reports the results of our research in monetary economics applied to the housing market, including some novel data analysis, a new theory, and a calibration exercise. In fact, the theory is not so much new as a combination of three existing literatures. The basic framework follows the now standard approach to the microfoundations of monetary theory, sometimes called New Monetarist Economics, that provides benchmark models of money, credit, banking, over-the-counter financial markets and related phenomena. Into this we introduce household production, since we believe it is best to think about home capital (residential structures and consumer durables) as a factor of production, parallel to the way economists think about market capital (nonresidential structures and producer durables). Then we import features from the literature that studies the production of houses, because we are interested in the supply side as well as the demand side of housing markets. Although each of these elements has been studied extensively, they have not been previously interrelated. ${ }^{1}$

As one motivation for the project, consider the often-heard view that there is a connection between monetary policy and housing markets. While there may be several ways to think about such a connection, one is the common notion that housing is a good hedge against inflation. That notion is vague, but the interpretation adopted here is this: the value of housing wealth increases when inflation is higher. By a hedge, we do not mean that one can use housing to avoid inflation risk, although that may also be interesting; the idea is rather that having more housing

\footnotetext{
${ }^{1}$ Since we are combining several different literatures we cannot list every relevant paper. On the microfoundations of monetary economics, we discuss below the work on which we build directly, but see Williamson and Wright $(2010 a, b)$ and Nosal and Rocheteau (2011) for recent surveys. On home production, there are surveys by Greenwood et al. (1995) and Gronau (1997), although there has been a lot of work since then, as discussed below. We also review some housing research, but an example of what we have in mind is Davis and Heathcote (2005).
} 
allows one to partially avoid some of the effects of anticipated inflation. A goal of the paper is to make this precise, but to get some rough intuition, consider the so-called Tobin effect that says that inflation makes agents want to substitute out of cash and into capital. Our effect is similar, except we focus on household instead of market capital. To put it differently, in most monetary models, inflation makes agents want to substitute out of consumption and into leisure; in our model they substitute into household production.

While part of the objective is methodological - integrating approaches from different literatures into a framework that can be useful in a variety of applications - we also want to discuss some substantive issues. First we check the facts, using various data sources, for the U.S. and other countries. We construct from different sources several measures of housing wealth, scaled by either nominal output or by the money supply (one has to scale by something, obviously, to control for purely nominal effects). We then show these series for housing wealth are positively related to nominal interest and inflation rates. Although one may be able to think of different explanations for this evidence, we pursue the idea that inflation is a tax on market activity. This is surely relevant in high-inflation, cash-intensive economies, but it is also interesting to explore the channel for the U.S. Inflation and nominal rates have been low here for a while, but the 1970s runup and subsequent decline provide plenty of variation in the data. And as regards cash intensiveness, note that inflation impacts not only currency but many other assets. ${ }^{2}$

By way of example, higher inflation or nominal interest rates provide an incentive to go out for dinner less and eat more meals at home, as long as going out is relatively cash intensive. Now, not all market activity uses cash, but it uses cash

\footnotetext{
${ }^{2}$ It obviously affects demand deposits, especially when interest payments on these are quite low, but more generally inflation affects the returns to all liquid assets. See Lester et al. (2012) and Venkateswaran and Wright (2013) for models making this point theoretically and quantitatively.
} 
more than household activity, since goods like home-cooked meals are not even traded, let alone traded using currency. Thus, inflation increases the demand for home-production inputs, which raises the value of housing wealth, through prices, and through quantities as construction catches up. Quite generally, as long as high inflation or nominal interest rates discourage market activity, and thus encourage household activity, they should affect the demand for housing.

Another reason for integrating these literatures is the following. A classic questions in economics asks about the effect of inflation on welfare. One should think that the answer will be affected by incorporating home production, given that much previous work has shown that adding it to otherwise standard models makes a significant difference for various other quantitative questions. ${ }^{3}$ Typically, the main impact of incorporating home production is that it changes the amount by which agents respond to changes in policy and other forcing variables. In the standard macro model, agents can substitute between leisure and labor and between consumption and investment. In models with home production, they can substitute between leisure and working in the market or working at home, and between consumption and investment in market capital or home capital. It has been shown that this significantly affects the quantitative impact of fiscal policy (by several of the papers in fn. 3); we want to know how it affects the impact of monetary policy.

To implement these ideas, the model of money and capital in Aruoba et al. (2011) is generalized to include home production and the production of homes (construc-

\footnotetext{
${ }^{3}$ Benhabib et al. (1991) and Greenwood and Hercowicz (1991) put ideas about home production by Becker $(1965,1988)$ into quantitative macro models, and show they match key business-cycle moments better than models without home production. Home production models also better explain consumption (Baxter and Jerrmann 1999; Baxter 2010; Aguiar and Hurst 2005,2007a), investment (Gomme et al.2001; Fisher 1997,2007), female labor-force participation (Greenwood et al.2005; House et al 2008; Albanesi and Olivetti 2009), and labor supply generally (Rios-Rull 1993; Rupert et al. 2000; Gomme et al. 2004; Aguiar and Hurst 2007b; Ngai and Pissarides 2008; Rogerson and Wallenius 2009). These models also give different answers to fiscal policy questions (McGrattan et al.1997; Rogerson 2009), and provide novel perspectives on development issues (Einarsson and Marquis 1997; Parente et al. 2000).
} 
tion). Housing capital, like market capital, is both produced and used in production. Following much of the work on home production, we make home capital a factor of production instead of inserting it directly in the utility function. We stay close to the approach in the earlier papers for the purposes of comparison, and because it allows us to take advantage of some results in the literature, including estimates of certain key elasticities. ${ }^{4}$

After providing analytic results that formalize the economic intuition, we calibrate the model, and ask how well it accounts for the empirical findings. The answer is that, depending on some details, we can account for between $22 \%$ and $52 \%$ of the relationship between interest rates and housing wealth over nominal output, and between $78 \%$ and $87 \%$ of the relationship between interest rates and housing wealth over the money supply. So, while the channel on which we focus is relevant, there is room for other factors to play a role. But of course the objective is not to explain $100 \%$; it is to show how the model can be used to measure the size of the effects, without prejudice as to whether they are big or small. We also show the welfare cost of inflation is higher than in similar models without home production. Again, the goal is not to make this number big or small but to investigate the impact of including home production.

To be clear about our methods, we generate quantitative predictions from theory in the counterfactual situation where the only impulses are changes in inflation or nominal interest rates. This is not because we believe changes in taxes, technology, demography and other factors are irrelevant; we simply want a controlled experiment, changing one variable holding the rest fixed. This is similar to standard

\footnotetext{
${ }^{4}$ The issue is similar to the way one handles the value of time. As discussed in the surveys cited in fn. 1, Becker's approach assumes time does not enter utility, but consumption does, and home work is an input into home production; by contrast, Gronau's approach assumes agents value leisure time per se, as well as home production. Neither is "better" but we need to pick one. As a benchmark, we assume time enters utility directly while capital does not.
} 
practice in macro going back to Kydland and Prescott (1982) of asking, e.g., what a model can explain based only on technology shocks. The paper is not about business cycles, however. It is about medium- to long-run phenomena, because we do not think a blip up in the CPI in one month causes people to abandon the market; we do believe that if people face relatively permanently higher inflation, they choose less market and more household activity. ${ }^{5}$

In terms of other work, there is work on the relationship between inflation and the stock market, which is related in that stocks and housing are both alternatives to monetary assets. ${ }^{6}$ Research analyzing housing and inflation through effects on mortgages include Kearl (1979), Follain (1982) and Poterba (1991). This is a complementary idea, and we do not want to "test" one hypothesis against the other, given our results leave room for other theories. Brunnermeier and Juiliard (2008) impose money illusion, confounding agents between nominal and real interest rates. Burnside et al. (2011) also depart from standard rational expectations. While this is fine, we want to see how far we can go with rational agents. He et al. (2011) show housing can bear a liquidity premium, somewhat like money, when it can be used to secure home-equity loans. To focus on other effects we abstract from this, which seems reasonable at least before 2000, when such borrowing was less important.

Piazzesi and Schneider (2010) assume inflation taxes the returns to financial assets but not housing. This is a complementary idea, too, although their model

\footnotetext{
${ }^{5}$ It is easy to introduce shocks to technology, policy and other variables, and look at highfrequency behavior, but that would be a distraction for present purposes. More importantly, we emphasize that our theory is not inconsistent with high-frequency evidence suggesting that monetary shocks are associated with market expansions rather than contractions. Over longer horizons, inflation and nominal interest rates move together, and the hypothesis that increases in these rates are bad for market activity at low frequencies does not contradict any findings in, e.g., Christiano et al. (2005). For a long-run analysis finding money growth, inflation and nominal interest rates move together, and increases are bad for market activity, see Berentsen et al. (2011).

${ }^{6}$ See Geromichalos et al. (2007) for references to work on the effects of inflation on the stock market. See Venkateswaran and Wright (2013) for a list of empirical papers looking at the effects on asset returns, more generally, as well as output and investment.
} 
is very different. To highlight two differences: (i) our monetary theory is built on relatively firm microfoundations; (ii) we incorporate home production. The first is relevant because we think of the paper as a contribution to monetary economics at least as much as a contribution to the housing literature. The second is relevant because we also think the paper is a contribution to the home production literature, and because this allows us to take advantage of results from that research, as mentioned above. To close these introductory remarks, we mention that although our model has a frictional retail goods market, which is essential for modeling money rigorously, housing is traded in a frictionless market. Actual markets for houses are far from frictionless, just like actual markets for factories, workers and other inputs, but to maintain focus, in this project, home capital and market capital are traded in perfect markets as in standard growth theory. ${ }^{7}$

The rest of the paper is organized as follows. Section 2 discusses data. Sections 3 presents the environment. Section 4 provides simple versions of the theory that deliver clean qualitative results. Section 5 generalizes this for quantitative analysis. Section 6 presents the calibration exercises. Section 7 concludes.

\section{Data}

Here we present the case that nominal interest or inflation rates are positively related to the value of home capital, scaled by nominal output or by the money supply to correct for purely nominal changes. We first examine the U.S., then other countries. For the U.S. we consider several measures of home capital, by which we mean the value (price times quantity) of the housing stock plus durable goods. We add durable goods because we think of home capital more broadly than just housing, even if

${ }^{7}$ The growing body of research on frictional housing markets includes Wheaton (1990), Albrecht et al. (2007), Caplin and Leahy (2008), Coulson and Fisher (2009), Ngai and Tenreyro (2009), Novy-Marx (2009), Piazzesi and Schneider (2009) and Head and Lloyd-Ellis (2012). 
housing is the lion's share (about 3/4). At least for appliances and related consumer durables, it seems natural to include them in home capital, parallel to the way producer durables are included in market capital. While data sources are discussed in the text, detailed information is given in the Appendix.

\subsection{United States}

Our baseline measure of housing wealth uses data from Davis and Heathcote (2007), $\mathrm{DH}$ for short. A disadvantage of these data is that the sample is relatively short, starting in 1975; an advantage is that they are quite accurate. Figure 1 shows time series in the left column, and scatter plots as well as correlations and semi-elasticities in the right column. The top row is home capital over nominal output versus the nominal interest rate on T-bills. As in most work on home production, our measure of output is GDP minus rents paid to housing services. The scatter plots show the predicted relationships for 1975-1999 and for 2000-2009.

The first issue to mention is that it is apparent that something unusual - often referred to as a bubble - was happening in the 2000s relative to the previous 25 years. This project is not about the post-2000 U.S. housing boom and bust, as there may well have been something going on that our model is not designed to capture, such as developments in financial markets, including the big increase in home-equity lending. ${ }^{8}$ The theory presented is not a model of bubbles. While it may be interesting in future work to extend it in that direction, it is also legitimate to see what the theory has to say about more "normal" times. This suggests that

\footnotetext{
${ }^{8}$ As Holmstrom and Tirole (2011) put it, "In the runup to the subprime crisis, securitization of mortgages played a major role ... by making nontradable mortgages tradable [and this] led to a dramatic growth in the US volume of mortgages, home equity loans, and mortgage-backed securities in 2000 to 2008." Ferguson (2008) and Reinhart and Rogoff (2009) characterize the situation by saying this lead to households treating their houses as ATM machines. See Mian and Sufi (2011) for more discussion of the episode, and He et al. (2011) for a model in which home-equity lending can generate bubbles with housing-fueled expansions and collapses.
} 
it may be reasonable to stop the sample at the end of the last millennium, but we do not want to hide anything, and so we show what happened after 2000, too.

From 1975 to 1999, home capital is clearly positively correlated with the T-bill rate. This is also true after 2000, with a nearly-parallel shift up in the relationship. The semi-elasticity for the $1975-1999$ period is 1.1 , and the correlation is 0.62 . This is the first key empirical finding: nominal interest rates are positively related to the value of home capital scaled by nominal output. One of the primary goals of the quantitative work is to see how well theory can account for this relationship. Before moving to models, however, we want to investigate the robustness of the facts. The second row in Figure 1 deflates home capital by the money supply, instead of nominal output, where our measure of money is the M1S series that adjusts M1 for the practice since the 1990s of sweeping checkable deposits into overnight money market accounts (Cynamon et al.2006). This is the second key empirical finding: Home capital scaled by the money supply is even more strongly positively with the nominal rate, with a semi-elasticity around 3.7 and a correlation of 0.8 .

To further check robustness, the third row in Figure 1 replaces the T-bill rate with the AAA corporate bond rate. Before 2000, the relationship between home capital scaled by the money supply is similar to what we found with the T-bill rate, again with a correlation around 0.8. Although after 2000 the relationship looks different, there is not much information in that short subsample. The last row of Figure 1 uses the inflation rate instead of the nominal interest rate. According to the Fisher Equation, nominal interest rates move one-to-one with inflation, but while this is approximately true in the longer run it is not exactly true in the shorter run. The results are similar, although now the post 2000 data look like more like a rotation than a shift in the relationship, but again there is not much information in that short subsample. We slightly prefer nominal interest rates (rather than inflation) as 
a measure of the wedge imposed by monetary policy, because they are arguably a better measure (than contemporaneous inflation) of expected future inflation, which is what matters in the model.

To further investigate the facts, we now consider several alternative ways to measure the value of home capital, using different data sets, some of which extend over much longer samples. This is shown in Figure 2. The first row presents the scatter between home capital scaled by nominal output, and scaled by the money supply, against the T-bill rate, where the measure of housing wealth now uses data from the Flow of Funds Accounts (FFA). An advantage of FFA data is that they go back to 1952 , although we think it is probably better to start in 1955 , due to possible effects from the Korean War. However, a disadvantage is that FFA data do not provide the best estimates of house values for 1975-1990, which is a key part of the sample because it has a lot of variation in inflation. ${ }^{9}$ Having said that, the relationships in this data are very similar to those in Figure 1.

The second row in Figure 2 uses housing wealth data based on the replacement cost of structures estimated by the Bureau of Economic Analysis (BEA). A disadvantage here is that these data do not include the value of land, which prior to 1970 was between 10 to 20 percent, and is currently about a third of housing value (Davis and Heathcote 2007). An advantage is that they are constructed according to well-documented methods and go back to the 1930s, although it is less clear what to make of data that far back, where the situation is confounded by the Great Depression, as well as some swings in inflation and interest rates probably having to do with wars and price controls. In this case the regression lines come from splitting the sample between 1930-1954 and 1955-1999, and we use the AAA bond rate,

\footnotetext{
${ }^{9}$ This is because the housing capital gains implied by the FFA data over this period do not align well with capital gains computed using standard price indexes. Unlike the DH data, where capital gains are taken directly from price indexes, for this period FFA data spline together estimates from various surveys. See Davis and Heathcote (2007) for details.
} 
which is readily available going back to the 1930s. For the 1955-1999 period, the relationship in this data is even stronger than the results in Figure 1. The third row in Figure 2 is housing wealth computed directly from the Decennial Censuses of Housing (DCH). The advantage here is that the numbers are very accurate, and go back to 1930, but we only get one observation every ten years, so we interpolate. Once again, there is a very strong relationship.

The last row of Figure 2 uses Shiller's (2005) house price index (HPI), starting in 1955. The relationship in the right panel looks like the previous rows; the left panel does not. But we believe there are some issues with using HPI data for our purposes. Table 1 reconciles decade-by-decade changes in HPI and housing wealth as follows: Column 1 reports HPI growth; Column 2 reports growth in the average price of housing units; Column 3 reports growth in the number of units; and Column 4 reports growth in nominal GDP. The percentage change in the value of housing is approximately Column 2 plus Column 3. Columns 1 and 2 show average prices rise faster than the HPI in every decade. This is because Shiller's data hold quality constant, and the gap between Columns 1 and 2 reflects quality improvement. Also, these data do not track changes in the number of units, which rose rapidly over the sample. Columns 2 and 3 show the change in housing wealth between 1950 and 2000 is 528 percent, about the same the 517 percent change in nominal GDP. The HPI increased only 284 percent. This implies the HPI is not so useful for our purposes, and may explain why those who focus on this data have not noticed the facts found in all the other sources. ${ }^{10}$

\footnotetext{
${ }^{10}$ We also mention Brunnemeier and Julliard (2007), who find that nominal interest rates forecast one-period-ahead price-rent ratios. The relationship is negative and statistically significant. They also find nominal rates forecast deviations of the price-rent ratio from trend. These findings are in no way inconsistent with our results. For one thing, price-rent ratios are not the same as value-income ratios, which are the objects of interest here - e.g., the former can reflect discount factors, while the latter reflect the desirability of housing wealth relative to one's budget. Moreover, we are less interested in one-period-ahead forecasting than long-run relationships.
} 


\subsection{Other Countries}

Data on housing wealth prior to 1990 , and certainly prior to 1980 , are virtually nonexistent outside the U.S., but estimates of prices have been constructed for several countries. As we said, we prefer price times quantity, but for most countries prices are the best we can get. Figure 3 presents house prices over nominal output versus inflation for 16 countries. ${ }^{11}$ Inflation is used because it is harder to get consistent measures of interest rates across countries, and now we do not distinguish between the pre- and post-2000 data, because the boom and bust are less apparent in these economies than in the U.S. The bottom line is that there is a positive relationship between the house price index and inflation in 13 out of 16 countries. Although we would prefer to have data on price times quantity, instead of a price index, these findings are at least supportive of our general hypothesis.

\subsection{Summary of the Facts}

The clear preponderance of evidence from the information we were able to uncover - and we made every effort to cast our net widely - indicates that there is a positive relationship between appropriately-scaled housing wealth, or house prices when we could not get data on housing wealth, and nominal interest or inflation rates. The rest of the paper presents one way of trying to account for the evidence. Our final word on the data is to mention a comment by Jeff Campbell, who suggested that one might well ask whether it is better interpret the findings in terms of an event or a moment - i.e., the impact of one big rise and fall in post-war inflation or a repeated pattern in the time series. Although the question is interesting, we do

\footnotetext{
${ }^{11}$ Direct source data were used for Belgium, France, Ireland, Switzerland and the UK. For the remaining countries, we use 1971-2009 data from the BIS (Bank for International Settlements) discussed in Andre (2010). We are less sure about those data, since we do not know the original sources, but we checked price growth against source data for the five economies mentioned above, and they align well. This gives us some confidence in the BIS numbers.
} 
not provide an answer. For our purposes it seems fine to think of it as an event, although Figure 1 suggests it is something more, as the time series look to us to cohere fairly well not only in one episode. In either case, we contend that the facts are interesting and worth studying with quantitative models.

\section{Environment}

Our framework builds on the textbook home-production macro model presented in Greenwood et al. (1995). The main differences are: (i) we go into more detail concerning the production of houses; and (ii) we go into more detail concerning retail trade. As regards (ii), in particular, we make assumptions on the environment that allow some retail trades to use credit, but force others to use cash. To illustrate the key economic insights, we first analyze two relatively simple models, then generalize in order to address the issues quantitatively. However, since the baseline environment is similar in all the models, we begin by discussing that.

Time is discrete and continues forever. It is convenient to separate each period into two subperiods, where in the first agents trade inputs and adjust their portfolios, while in the second they consume. The set of agents consists of: a $[0,1]$ continuum of homogeneous households; a $[0, n]$ continuum of retail firms, where $n$ matters because it affects trading probabilities in the retail market; and some set of production firms, the cardinality of which does not matter due to constant returns and the fact that these firms trade in frictionless markets. There is also a government that exogenously each period sets the money supply $M$ and levies a lump sum tax $T$. We consider processes for $M$ of the form $M^{\prime}=(1+\mu) M$, and focus on stationary outcomes where all real variables are constant. This implies that inflation is pinned down by the rate of monetary expansion, $\pi=\mu$, a version of the Quantity Equation. Also, the nominal interest rate is pinned down by the Fisher Equation $1+i=(1+\rho)(1+\pi)$, 
where $\rho$ is the real rate. In steady state, $1+\rho=1 / \beta$ where $\beta \in(0,1)$ is the discount factor. ${ }^{12}$ Given this, we take $i$ to be the monetary policy instrument, but it would be equivalent to use $\mu$ or $\pi$.

In the first subperiod, production firms hire labor and capital from households at nominal factor prices $w$ and $r$ to make output $x$. Households purchase $x$, supply labor and adjust their portfolios. Retailers purchase $x$ and transform it into a different good that they sell in the second subperiod. Household utility is

$$
u\left(c_{x}, c_{m}, c_{n}\right)-A_{m} \ell_{m}-A_{n} \ell_{n}
$$

where $c_{x}, c_{m}$ and $c_{n}$ are consumption of first-subperiod output, of the retail market good, and of a nonmarket or home-produced good, while $\ell_{m}$ and $\ell_{n}$ are market and nonmarket labor hours. As in many other macro models with home production (see Greenwood et al. 1995) utility is linear in labor, which is useful here for tractability (see fn. 15). Also, for many results we can eliminate $c_{x}$, so that there are just two goods, but it is important to have $c_{x}$ in the quantitative work to match certain observations (including observations on velocity, as discussed in Dressler, 2011). As usual, $u(\cdot)$ is strictly increasing and concave.

There are two nominal assets: money $m$ and bonds $b$. The role of $m$ is to serve as a medium of exchange in some retail transactions, while $b$ is there merely to compute the nominal interest rate on an illiquid asset - i.e., bonds are not traded in equilibrium but we can still price them. There are three real assets: market capital $k_{m}$; residential structures $k_{s}$; and land $k_{l}$. As always, $k_{m}$ is an input to the market production function $f\left(\ell_{m}, k_{m}\right)$. Symmetrically, there is a nonmarket production function $g\left(\ell_{n}, k_{n}\right)$, where $k_{n}$ is nonmarket capital, which we sometimes call housing, even if in the empirical work we add consumer durables. Housing

\footnotetext{
${ }^{12}$ Agents discount across periods, but not across subperiods, without loss of generality (one can subsume discounting between subperiods in the notation).
} 
combines residential structures and land according to $k_{n}=h\left(k_{s}, k_{l}\right)$. One could alternatively say that the nonmarket production function $g(\cdot)$ has three inputs, labor, structures and land, but in the quantitative analysis it is useful to have housing as an explicit function of $k_{s}$ and $k_{l}$.

To keep the notation manageable we abstract from land in the market technology $f(\cdot)$, although when we did include it, the results were similar. This makes sense, given that market production is not especially land intensive (e.g., Davis et al. 2014 calculate a share of only $2.6 \%$ ) compared to the production of housing. Also, in the baseline model $k_{n}$ only affects the production of $c_{n}$, and it is $c_{n}$ that enters $u(\cdot)$, following previous macro models with home production. However, one version analyzed below sets $g\left(\ell_{n}, k_{n}\right)=k_{n}$, in which case one can say $k_{n}$ enters $u(\cdot)$ directly. Market capital and structures depreciate at rates $\delta_{m}$ and $\delta_{s}$; land does not depreciate, and the supply is fixed at $K_{l}$. The technologies $f(\cdot), g(\cdot)$ and $h(\cdot)$ are strictly increasing and concave. We often assume they also display constant returns to scale, although for most of the analytic results it typically suffices to assume normal inputs. ${ }^{13}$

While inputs and assets are traded in a frictionless market in the first subperiod, the exchange process is more intricate in the second subperiod, where there are two retail locations. In one, agents have access to record keeping, and hence are able to trade using credit; in the other where they have no such access and hence must use money. Which retail location a household visits - the money market or the credit market - is exogenous. As this is not the place to go into detail concerning microfoundations that make money essential, or that allow money and credit to coexist, we refer readers to the surveys mentioned in fn. 1 , but also mention

\footnotetext{
${ }^{13}$ Because this condition is used for several results, here we define normal inputs explicitly. Consider the problem $\min \{w \ell+r k\}$ st $f(\ell, k)=x$. It is routine to derive $\partial \ell / \partial x=\Delta\left(f_{2} f_{12}-f_{1} f_{22}\right)$ and $\partial k / \partial x=\Delta\left(f_{1} f_{21}-f_{2} f_{11}\right)$, where $\Delta>0$. Thus, $\ell$ is normal iff $\partial \ell / \partial x>0$, which means $f_{2} f_{12}>f_{1} f_{22}$. Symmetrically, $k$ is normal iff $f_{1} f_{21}>f_{2} f_{11}$.
} 
that our setup is basically the same as the one used to good effect by Sanches and Williamson (2010). To be clear, credit here means acceptance by retailers of households' promises to pay next period for goods now. We want some monetary exchange because the empirical issues in question concern monetary phenomena, and we want some credit in order to match in the quantitative work the fractions of retail trade that use different payment instruments.

The measures of households visiting the two locations are $\sigma_{1}$ and $\sigma_{2}$, and they take these as the probabilities of being able to use money and of being able to use money or credit. It is useful for some issues to allow a measure $\sigma_{0}=1-\sigma_{1}-\sigma_{2}$ of households to not trade at all. There are obvious interpretations of $\sigma_{j}$ 's in terms of search theory, although there are also other interpretations (e.g., they can be generated by preference and technology shocks). To remember the notation, the $j$ in $\sigma_{j}$ refers to the number of payment instruments available: with probability $\sigma_{1}$ there is one, money; with probability $\sigma_{2}$ there are two, money and credit; and probability $\sigma_{0}$ there are none. Purely to ease notation, we assume the ratio of households to retailers (market tightness) is the same in the two locations, and since the ratio of all retailers to all households is $n$, a given retailer trades in the credit market with probability $\min \left\{\sigma_{2} / n, 1\right\}$ and in the money market with probability $\min \left\{\sigma_{1} / n, 1\right\} .{ }^{14}$

Finally, to close the description of the environment, we assume that all agents are Walrasian price takers in all markets. Much of the New Monetarist literature allows for alternatives to price-taking, including bargaining, posting and more abstract mechanisms (see Rocheteau and Wright 2005, or the surveys mentioned in fn. 1, for extended discussions). We use price taking because it is familiar, easy, and facilitates comparison with previous work on home production and housing.

\footnotetext{
${ }^{14} \mathrm{~A}$ pure-currency (pure-credit) retail market is the special case with $\sigma_{2}=0\left(\sigma_{1}=0\right)$. A nonmonetary version is relevant because we think the framework can be applied to many other issues related to housing and home production, and for some of these applications, it may be appropriate to abstract from monetary exchange.
} 


\section{Simple Models}

We now present two relatively simple models to convey the intuition behind the theory. The first one fixes capital in order to analyze the effect of monetary policy on price holding the quantity of housing fixed. The second makes capital endogenous as in standard growth theory, where it is the same physical good as output and hence its price relative to output is 1 , to analyze effects on the quantity of market and home capital. The general model has both, but these versions allow us to isolate the economic forces. Also, here we ignore bonds, and set $\sigma_{2}=0$ so there is no retail credit. Moreover, for now, households get no direct utility from first-subperiod output, so we write the utility of consumption as $U\left(c_{m}, c_{n}\right) \equiv u\left(0, c_{m}, c_{n}\right)$. It is a maintained hypothesis that $c_{m}$ and $c_{n}$ are substitutes: $U_{12}(\cdot)<0$.

\subsection{Price Effects}

In this first case, we fix market capital and structures at $k_{m}=K_{m}$ and $k_{s}=K_{s}$, and set $\delta_{m}=\delta_{s}=0$, thus treating them like land. Then the housing stock is fixed at $K_{n}=h\left(K_{s}, K_{l}\right)$. Rather than trading structures and land separately, it suffices to let households trade home capital $k_{n}$ directly at price $p_{n}$. Similarly, they trade market capital $k_{m}$ at price $p_{m}$. Further, we simplify the household problem by assuming that home production takes no time, $c_{n}=g\left(\ell_{n}, k_{n}\right)=k_{n}$. Hence, in this simple model, one can say that home capital enters $U(\cdot)$ directly.

At the start of a period, a representative household's state variable is a portfolio $\mathbf{z}=\left(m, k_{m}, k_{n}\right)$, and the choice variables are a new portfolio $\hat{\mathbf{z}}$ as well as labor supply. Let $W(\mathbf{z})$ and $V(\hat{\mathbf{z}})$ be the value functions in the first and second subperiods. Then the first-subperiod problem is

$$
W(\mathbf{z})=\max _{\hat{\mathbf{z}}, \ell_{m}}\left\{-A_{m} \ell_{m}+V(\hat{\mathbf{z}})\right\} \text { st } \hat{m}=w \ell_{m}+\Omega-p_{m} \hat{k}_{m}-p_{n} \hat{k}_{n}
$$


where $\Omega$ is market capital income plus net after-tax wealth,

$$
\Omega=\left(r+p_{m}\right) k_{m}+p_{n} k_{n}+m-T \text {. }
$$

Eliminating $\ell_{m}$ leads to the pure portfolio problem of choosing $\hat{\mathbf{z}}$ given $\mathbf{z}$ :

$$
W(\mathbf{z})=\max _{\hat{\mathbf{z}}}\left\{\frac{A_{m} \Omega}{w}-\frac{A_{m}}{w}\left(\hat{m}+p_{m} \hat{k}_{m}+p_{n} \hat{k}_{n}\right)+V(\hat{\mathbf{z}})\right\} .
$$

Notice $W$ is linear in $\Omega$ with slope $A_{m} / w$. Also, the choice of $\hat{\mathbf{z}}$ is independent of $\Omega$ : those with more (less) wealth work less (more), but they choose the same portfolio. ${ }^{15}$

In the second subperiod agents consume $\left(c_{m}, c_{n}\right)$, limited by the following considerations. First, $c_{n}=k_{n}$ is limited by the home capital brought out of the previous period. Second, they only have a retail trading opportunity with probability $\sigma_{1}$. Hence, with probability $\sigma_{0}=1-\sigma_{1}$ they get $c_{m}=0$, and with probability $\sigma_{1}$ they get $c_{m}=\hat{m} / p_{1}$, where $p_{1}$ is the retail price and we use the standard result that they bring just the amount of cash that they want to spend. Therefore,

$$
V(\hat{\mathbf{z}})=\sigma_{0}\left[U\left(0, \hat{k}_{n}\right)+\beta W(\hat{\mathbf{z}})\right]+\sigma_{1}\left[U\left(\hat{m} / p_{1}, \hat{k}_{n}\right)+\beta W(\hat{\mathbf{z}})-\beta \hat{m} \frac{A_{m}}{w^{\prime}}\right]
$$

using in the second term on the RHS the result that next period $W(\hat{\mathbf{z}})$ will be linear in wealth with slope $A_{m} / w^{\prime}$, where $w^{\prime}$ is next period's wage.

As regards retailers, in the first subperiod they purchase $x$ and convert it onefor-one into the retail good, which they then try to sell in the second subperiod, where they get a customer with probability $\sigma_{1} / n$. Assume for simplicity that any unsold inventory fully depreciates when the retail market closes. Then retailers supply their wares inelastically: $c_{m}=x$. Hence, expected profit for a retailer is

\footnotetext{
${ }^{15}$ As in Lagos and Wright (2005), this history independence ( $\hat{\mathbf{z}}$ independent of $\mathbf{z}$ ) is the major simplification that results from having quasi-linear utility, although as shown recently by Wong (2012), this can be relaxed to allow a much larger class of utility functions. In principle, one does not need history independence, if one were willing to do more computational work, as in Chiu and Molico (2010, 2011).
} 
$p_{1} x\left(\sigma_{1} / n\right)(1+i)-p_{x} x$, which is the trade probability $\sigma_{1} / n$ times discounted revenue $p_{1} x(1+i)$, minus the cost of inventories $p_{x} x$. Since expected profit is linear in $x$, in equilibrium we must have

$$
p_{x}=p_{1} \frac{\sigma_{1}}{n}(1+i) .
$$

As usual, factor prices satisfy $w=p_{x} f_{1}\left(\bar{\ell}_{m}, K_{m}\right)$ and $r=p_{x} f_{2}\left(\bar{\ell}_{m}, K_{m}\right)$, where $\bar{\ell}_{m}$ is aggregate employment and $K_{m}$ is the (for now) exogenous stock of market capital. To be clear, for each individual household, $\ell_{m}=\ell_{m}(\Omega)$ depends on wealth at the start of the period, and that depends on their experience in the previous retail market, as they may or may not have money left over. However, to characterize macro equilibrium, all we need is $\bar{\ell}_{m}=\int \ell_{m}(\Omega)$ (a precise definition of equilibrium is given below). Then, to get the nominal price level, use $\hat{m} / p_{1}=c_{m}=x$ and (3) to write $p_{x}=M \beta\left(\sigma_{1} / n\right) x$. In equilibrium, first-subperiod market clearing implies $x=f\left(\bar{\ell}_{m}, K_{m}\right)$. To say more, combine the FOC from (1) with the derivatives from (2) to get the Euler Equations ${ }^{16}$

$$
\begin{aligned}
\hat{m} & : \quad \frac{A_{m}}{w}=\frac{\sigma_{1} U_{1}\left(\hat{m} / p_{1}, k_{n}\right)}{p_{1}}+\frac{\left(1-\sigma_{1}\right) \beta A_{m}}{w^{\prime}} \\
\hat{k}_{m} & : \quad \frac{p_{m} A_{m}}{w}=\frac{\beta\left(r^{\prime}+p_{m}^{\prime}\right) A_{m}}{w^{\prime}} \\
\hat{k}_{n} & : \quad \frac{p_{n} A_{m}}{w}=\frac{\beta p_{n}^{\prime} A_{m}}{w^{\prime}}+\sigma_{1} U_{2}\left(\hat{m} / p_{1}, k_{n}\right)+\left(1-\sigma_{1}\right) U_{2}\left(0, k_{n}\right) .
\end{aligned}
$$

We can rearrange (4) to get

$$
A_{m}\left(i+\sigma_{1}\right)=\frac{\sigma_{1}^{2}}{n} U_{1}\left[f\left(\bar{\ell}_{m}, K_{m}\right), K_{n}\right] f_{1}\left(\bar{\ell}_{m}, K_{m}\right) .
$$

This is one equation in the one unknown $\bar{\ell}_{m}$, and immediately implies

$$
\frac{\partial \bar{\ell}_{m}}{\partial i}=-\frac{n^{2} A_{m}}{D}<0
$$

${ }^{16}$ These have simple economic interpretations - e.g., (4) sets the marginal cost of a dollar on the LHS to the marginal benefit on the RHS, since it is spent in the retail market with probability $\sigma_{1}$ and carried into the next period with probability $1-\sigma_{1}$. 
where $D=-\sigma_{1}^{2}\left(n U_{1} f_{11}+f_{1}^{2} U_{11}\right)>0$. That is, people work less in the market in an economy with higher inflation. Of course $c_{m}$ moves in the same direction as $\bar{\ell}_{m}$ with $k_{m}$ fixed.

These kinds of effects, of $i$ on $c_{m}$ and $\ell_{m}$, are standard in monetary theory. To derive some more novel results, solve (5)-(6) in steady state for

$$
p_{m}=\frac{\beta p_{x} f_{2}\left(\bar{\ell}_{m}, K_{m}\right)}{1-\beta} \text { and } p_{n}=\frac{p_{x} f_{1}\left(\bar{\ell}_{m}, K_{m}\right) \mathbb{E} U_{2}}{A_{m}(1-\beta)}
$$

where $\mathbb{E} U_{2}=\left(1-\sigma_{1}\right) U_{2}\left(0, k_{n}\right)+\sigma_{1} U_{2}\left(\hat{m} / p_{1}, k_{n}\right)$. The relative price of $k_{n}$ can now be calculated, in different ways, as follows. First, let $p_{c}$ be the average retail price, which in this model is $p_{c}=p_{1}$. The price of $k_{n}$ deflated by consumer (or retail) prices, and the price deflated by producer (or wholesale) prices, are then given by

$$
\frac{p_{n}}{p_{c}}=\frac{\sigma_{1} \mathbb{E} U_{2} f_{1}\left(\bar{\ell}_{m}, k_{m}\right)}{A_{m}(1-\beta) n(1+i)} \text { and } \frac{p_{n}}{p_{x}}=\frac{\mathbb{E} U_{2} f_{1}\left(\bar{\ell}_{m}, k_{m}\right)}{A_{m}(1-\beta)}
$$

It is now straightforward to derive

$$
\begin{aligned}
\frac{\partial}{\partial i} \frac{p_{n}}{p_{c}} & =\frac{\sigma_{1}^{3} f_{1}^{3}\left(U_{11} \mathbb{E} U_{2}-U_{1} \mathbb{E} U_{21}\right)-\left(1-\sigma_{1}\right) \sigma_{1} A_{m} n\left(n f_{11} \mathbb{E} U_{2}+f_{1}^{2} \mathbb{E} U_{21}\right)}{A_{m}(1-\beta) n(1+i)^{2} D} \\
\frac{\partial}{\partial i} \frac{p_{n}}{p_{x}} & =\frac{-n\left(n f_{11} \mathbb{E} U_{2}+f_{1}^{2} \mathbb{E} U_{21}\right)}{(1-\beta) D}>0
\end{aligned}
$$

For $p_{n} / p_{c}$, the first term in the numerator is negative if $k_{n}$ is a normal good, while the second is positive given that $c_{m}$ and $c_{n}$ are substitutes. If $\sigma_{1}=1$ (no search frictions) the second term vanishes and $p_{n} / p_{c}$ falls with $i$; when $\sigma_{1}<1$ the net result is ambiguous. By contrast, for $p_{n} / p_{x}$ the result is unambiguous: it rises with $i$. So, while it is possible that the relative price of $k_{n}$ rises with $i$, it depends on what we put in the denominator, and on the extent of retail market frictions. More definitive predictions emerge when we alternatively deflate by the money supply,

$$
\frac{\partial}{\partial i} \frac{p_{n}}{M}=-\frac{\beta \sigma_{1}\left[c_{m} f_{1}^{2} \mathbb{E} U_{21}+\left(c_{m} n f_{11}-f_{1}^{2}\right) \mathbb{E} U_{2}\right]}{(1-\beta) c_{m}^{2} D}>0
$$


More definitive predictions also emerge when we deflate by nominal GDP defined using producer or consumer prices: one can check that $p_{n} / p_{x} x$ is unambiguously increasing in $i$, while $p_{n} / p_{c} c_{m}$ is increasing in $i$ at least as long as households are not too risk averse. ${ }^{17}$

This is a key analytic result: Higher nominal interest rates raise the price of housing deflated either by the money supply or by nominal output. The economic intuition behind these findings is simple: Basically, inflation creates an incentive to move economic activity out of the market and into the home. This increases demand for the inputs to home production, which in general means $\ell_{n}$ and $k_{n}$. Heuristically, with $k_{n}=K_{n}$ fixed, higher demand can only increase the price, but generally it should increase the value $p_{n} k_{n}$, relative to some deflator. When we use either the money supply or nominal output as the deflator, the analytic predictions are right in line with this intuition.

The results can be generalized to put time back into home production, $c_{n}=$ $g\left(\ell_{n}, k_{n}\right)$. For illustration, set $n=\sigma_{1}=1$. Following the above procedure, we get

$$
\begin{aligned}
(1+i) A_{m} & =U_{1}\left[f\left(\bar{\ell}_{m}, K_{m}\right), g\left(\ell_{n}, K_{n}\right)\right] f_{1}\left(\bar{\ell}_{m}, K_{m}\right) \\
A_{n} & =U_{2}\left[f\left(\bar{\ell}_{m}, K_{m}\right), g\left(\ell_{n}, K_{n}\right)\right] g_{1}\left(\ell_{n}, K_{n}\right)
\end{aligned}
$$

These equations exhibit an elegant symmetry between market and home work, broken only by the former being taxed by $i$ while the latter is not. Then

$$
\frac{\partial \bar{\ell}_{m}}{\partial i}=\frac{A_{m}\left(U_{2} g_{11}+g_{1}^{2} U_{22}\right)}{\tilde{D}}<0 \text { and } \frac{\partial \ell_{n}}{\partial i}=-\frac{A_{m} f_{1} g_{1} U_{21}}{\tilde{D}}>0 \text {, }
$$

where $\tilde{D}>0$. With $k_{m}$ and $k_{n}$ fixed, $c_{m}$ and $c_{n}$ move in the same direction as $\bar{\ell}_{m}$

$$
\begin{aligned}
& { }^{17} \text { One can show the derivative of } p_{n} / p_{c} c_{m} \text { with respect to } i \text { is proportional to } \\
& \sigma_{1}^{3} f_{1}^{3} \mathbb{E} U_{2}\left(c_{m} U_{11}+U_{1}\right)-\sigma_{1}^{3} f_{1}^{3} U_{1} \mathbb{E} U_{21} c_{m}-\left(1-\sigma_{1}\right) \sigma_{1} A n\left[\left(n f_{11} c_{m}-f_{1}^{2}\right) \mathbb{E} U_{2}+c_{m} f_{1}^{2} \mathbb{E} U_{21}\right] .
\end{aligned}
$$

The second and third terms on the RHS are positive, while the first term is positive iff $-c_{m} U_{11}<$ $U_{1}$. Hence, as long as risk averse is not too high, the net effect is positive. 
and $\ell_{n}$. Hence, increases in $i$ lower market work and consumption, and raise home work and consumption. Increases in $i$ also raise $p_{n} / p_{x}$ and $p_{n} / M$.

\subsection{Quantity Effects}

The second simple model maintains $n=\sigma_{1}=1$ and $c_{x}=0$, but now market and home capital are endogenous. As in standard growth theory, both market and home capital are the same physical objects as output. ${ }^{18}$ We now present the equilibrium equations, without derivation, since they are special cases of the general model discussed below. First, we have two conditions for $\ell_{m}$ and $\ell_{n}$, exactly like (8)-(9) in the first simple model,

$$
\begin{aligned}
(1+i) A_{m} & =U_{1}\left(c_{m}, c_{n}\right) f_{1}\left(\bar{\ell}_{m}, k_{m}\right) \\
A_{n} & =U_{2}\left(c_{m}, c_{n}\right) g_{1}\left(\ell_{n}, k_{n}\right) .
\end{aligned}
$$

Next, we have steady state versions of the Euler Equations for $k_{m}$ and $k_{n}$,

$$
\begin{aligned}
\rho+\delta_{m} & =f_{2}\left(\bar{\ell}_{m}, k_{m}\right) \\
\rho+\delta_{n} & =f_{1}\left(\bar{\ell}_{m}, k_{m}\right) U_{2}\left(c_{m}, c_{n}\right) g_{2}\left(\ell_{n}, k_{n}\right) .
\end{aligned}
$$

Then we have the feasibility conditions,

$$
\begin{aligned}
c_{m} & =f\left(\bar{\ell}_{m}, k_{m}\right)-\delta_{m} k_{m}-\delta_{n} k_{n} \\
c_{n} & =g\left(\ell_{n} k_{n}\right) .
\end{aligned}
$$

One can differentiate (10)-(15) to get

$\hat{D} \frac{\partial k_{n}}{\partial i}=-|f| U_{2} g_{2}\left(U_{2} g_{11}+g_{1}^{2} U_{22}\right)-f_{1} U_{2} U_{21}\left(g_{1} g_{21}-g_{2} g_{11}\right)\left[\left(f_{2}-\delta_{m}\right) f_{21}-f_{1} f_{22}\right]$

${ }^{18}$ This is the specification in most home production models going back to Benhabin et al. (1991). What is missing here from the general model presented below is the following: a technology for producing houses by combining structures and land, which allows us to go beyond $p_{n} / p_{x}=1$; search frictions; retail credit; and the consumption good $c_{x}$. 
where $\hat{D}>0$ and $|f| \equiv f_{11} f_{22}-f_{12}^{2}$. The first term on the RHS is nonnegative, and vanishes if $f$ displays constant returns, while the second is positive given that $c_{m}$ and $c_{n}$ are substitutes while $\ell_{m}$ and $k_{n}$ are normal inputs. This is another key analytic result: An increase in $i$ unambiguously raises $k_{n}$. And the intuition is again simple: Higher nominal interest or inflation rates give households the incentive to substitute out of markets and into home activity. ${ }^{19}$ Given they want to engage in more home production, they demand more housing. Some other effects are ambiguous, including $\partial k_{m} / \partial i$ : first, $k_{m}$ falls with $i$ because $c_{m}$ does; then it rises because more $k_{m}$ is needed to produce the additional $k_{n}$ required to produce $c_{n} \cdot{ }^{20}$ Also, we cannot be sure of $\partial \ell_{m} / \partial i$ or $\partial \ell_{n} / \partial i$, in general, although $\partial \ell_{n} / \partial i>0$ is unambiguous if $f$ displays constant returns and we assume normal inputs. But the most important result is that $\partial k_{n} / \partial i>0$ is unambiguous.

\subsection{Summary of Analytic Results}

These simple models convey a lot of economic insight. There are two results to highlight. First, in the version with $k_{n}$ fixed, increases in $i$ raise the price of housing deflated either by the money supply or nominal output. Second, in the version with

${ }^{19}$ This is confirmed by deriving

$$
\begin{aligned}
\hat{D} \frac{\partial c_{m}}{\partial i}= & \delta_{n} U_{2} g_{2}|f|\left(U_{2} g_{11}+g_{1} U_{22}\right)-f_{1} U_{2}^{2}|g|\left[\left(f_{2}-\delta_{m}\right) f_{21}-f_{1} f_{22}\right] \\
& +f_{1} U_{2} U_{22}\left[\left(f_{2}-\delta_{m}\right) f_{21}-f_{1} f_{22}\right]\left(g_{1}+g_{2}\right)\left(g_{2} g_{12}-g_{1} g_{22}\right) \\
\hat{D} \frac{\partial c_{n}}{\partial i}= & g_{2} U_{2}|f|\left[U_{2}\left(g_{1} g_{21}-g_{2} g_{11}\right)-\delta_{n} g_{1}^{2} U_{21}\right] \\
& -f_{1} g_{1} U_{2} U_{21}\left[\left(f_{2}-\delta_{m}\right) f_{21}-f_{1} f_{22}\right]\left(g_{2} g_{12}-g_{1} g_{22}+g_{1} g_{21}-g_{2} g_{11}\right) .
\end{aligned}
$$

For $c_{m}$, given $\ell_{m}$ and $\ell_{n}$ are normal inputs, the first line is nonpositive and the second is negative. For $c_{n}$, given $\ell_{m}, \ell_{n}$ and $k_{n}$ are normal inputs, the first line is nonnegative and the second is positive. Hence, an increase in $i$ unambiguously lowers $c_{m}$ and raises $c_{n}$.

${ }^{20}$ This is confirmed by deriving

$$
\hat{D} \frac{\partial k_{m}}{\partial i}=g_{1} f_{1} U_{2} U_{22}\left(g_{2} g_{12}-g_{1} g_{22}\right)-f_{1} U_{2}^{2}|g|+f_{1} U_{2}\left(g_{1} g_{21}-g_{2} g_{11}\right)\left(g_{2} U_{22}-\delta_{n} U_{21}\right) .
$$

The first two terms are negative, but the third is ambiguous. 
$k_{n}$ produced like $k_{m}$ in standard capital theory, increases in $i$ raise the housing stock. Intuitively, higher $i$ is a higher tax on market activity; this makes households more inclined to move into home production; this increases demand for inputs to home production; and that leads to a rise in housing price or quantity.

The theory is also remarkably tractable, allowing us to either generate unambiguous predictions, or, when they are ambiguous, to see clearly the different effects. This is despite a rich structure, with home plus market production, multiple capital goods and frictional retail markets. For the rest of this paper, however, we generalize the environment and study it numerically. The generalizations are important for matching some facts, including the relationship between real balances and $i$, information on retail payment methods, and retail markups. Matching these facts is important for the applications at hand, because they concern the impact of monetary policy, and it improves confidence in the theory when it performs well in terms of standard monetary observations. Also, we bring back the technology for production of housing $k_{n}=h\left(k_{s}, k_{l}\right)$, which is important because then increases in demand can affect both the price and quantity of housing.

Before moving to the general model, however, at the request of a referee, we explain the method as follows. One endogenous variable on which we focus in the calibration exercise is $p_{n} k_{n} / p_{x} x$, where we show it increases in $i$ (a similar discussion applies to another variable on which we focus, $\left.p_{n} k_{n} / M\right)$. In theory one can decompose a change in this variable into the changes in each component, $p_{n}, k_{n}, p_{x}$ and $x$. From the analysis presented above, heuristically, an increase in $i$ raises $p_{n} / p_{x}$ and $k_{n}$ and reduces $x$, all of which contribute to the increase in $p_{n} k_{n} / p_{x} x$. While one might want to consider each component in the data when evaluating the theory, it only makes sense to consider stationary objects. One might hope that at least $p_{n} / p_{x}$ and $k_{n} / x$ are stationary, but this is not true in our data. In principle, we could build a 
model capturing the trends, but that goes beyond the current project. Hence, we concentrate on $p_{n} k_{n} / p_{x} x$, which is stationary in our data. ${ }^{21}$

\section{The General Model}

The state variable in the first subperiod now includes $\mathbf{z}=\left(m, b, k_{m}, k_{s}, k_{l}\right)$ plus outstanding debt from the previous period $d$, since some retail purchases are now made on credit (with quasi-linear utility we can restrict attention to one-period debt without loss in generality). Also, given we bring $c_{x}$ back, it is purchased in the first subperiod and becomes a state variable in the second. Hence, we write $W(\mathbf{z}, d)$ and $V\left(\hat{\mathbf{z}}, c_{x}\right)$ for the value functions. The generalization of $(1)$ is then

$$
W(\mathbf{z}, d)=\max _{\hat{\mathbf{z}}, c_{x}}\left\{\frac{A_{m} \Omega}{w}-\frac{A_{m}}{w}\left(\hat{m}+p_{x} c_{x}+p_{b} \hat{b}+p_{x} \hat{k}_{m}+p_{x} \hat{k}_{s}+p_{l} \hat{k}_{l}\right)+V\left(\hat{\mathbf{z}}, c_{x}\right)\right\},
$$

where now $\Omega=\left[r+p_{x}\left(1-\delta_{m}\right)\right] k_{m}+p_{x}\left(1-\delta_{s}\right) k_{s}+p_{l} k_{l}+m+b-T-d$. Notice $x, k_{m}$ and $k_{s}$ have the same price $p_{x}$, since they are the same physical good, but the price of housing $p_{n}$ is generally different. There are two equivalent ways to think about housing in this context. For now we assume households build their own homes using purchases of $k_{s}$ and $k_{l}$, but the outcome is exactly the same if they instead buy houses from construction firms, as discussed below. The important results are that again $W$ is linear in $\Omega$ and $\hat{\mathbf{z}}$ is independent of $\Omega$.

To proceed, we need to discuss the second subperiod in more detail. There are now three events that may occur for a household in the second subperiod: with probability $\sigma_{0}$ they have no opportunity to trade; with probability $\sigma_{1}$ they have an

\footnotetext{
${ }^{21}$ Although we cannot decompose in the data the change in $p_{n} k_{n} / p_{x} x$, we can in the model at steady state. By way of preview, in Calibration 1 below, $84 \%$ of the change in $p_{n} k_{n} / p_{x} x$ comes from a decline in $x, 4 \%$ comes from an increase in $p_{n} / p_{x}$ and $12 \%$ from an increase in $k_{n}$; and in Calibration 2, $65 \%$ of the change comes from a decline in $x, 9 \%$ comes from an increase in $p_{n} / p_{x}$ and $26 \%$ from an increase in $k_{n}$. So while we are getting a sizable effect from a fall in $x$, both $p_{n} / p_{x}$ and $k_{n}$ also behave in a way consistent with economic intuition.
} 
opportunity to trade using money; and with probability $\sigma_{2}$ they have an opportunity to trade using money or credit. Conditional on each event $j$, denote the value function by $V^{j}\left(\hat{\mathbf{z}}, c_{x}\right)$, and write $V\left(\hat{\mathbf{z}}, c_{x}\right)=\Sigma_{j} \sigma_{j} V^{j}\left(\hat{\mathbf{z}}, c_{x}\right)$. As in the simple model, when credit is not available, in money-only trade, households cash out. When credit is available, both buyers and sellers are indifferent between cash and credit as long as the value of the payment is the same, so without loss of generality assume they use credit only. This is all standard. What is more complicated is that households choose home work after knowing retail market outcomes, so there are different choices for $\left(c_{n}, \ell_{n}\right)$ in the cross section each period. ${ }^{22}$

For a household with no retail opportunity, $c_{m}^{0}=0$ and

$$
V^{0}\left(\hat{\mathbf{z}}, c_{x}\right)=\max _{c_{n}^{0}, \ell_{n}^{0}}\left\{u\left(c_{x}, 0, c_{n}^{0}\right)-A_{n} \ell_{n}^{0}+\beta W(\hat{\mathbf{z}})\right\} \text { st } c_{n}^{0}=g\left(\ell_{n}^{0}, \hat{k}_{n}\right)
$$

where it is understood that $\hat{k}_{n}=h\left(\hat{k}_{s}, \hat{k}_{l}\right)$. In this case, $\left(c_{n}^{0}, \ell_{n}^{0}\right)$ satisfies the constraint and the FOC $A_{n}=u_{3} g_{1}$. For a household with a cash-only opportunity, $c_{m}^{1}=\hat{m} / p_{1}$ and

$V^{1}\left(\hat{\mathbf{z}}, c_{x}\right)=\max _{c_{n}^{1}, \ell_{n}^{1}}\left\{u\left(c_{x}, \hat{m} / p_{1}, c_{n}^{1}\right)-A_{n} \ell_{n}^{1}+\beta\left[W(\hat{\mathbf{z}})-\hat{m} \frac{A_{m}}{w^{\prime}}\right]\right\}$ st $c_{n}^{1}=g\left(\ell_{n}^{1}, \hat{k}_{n}\right)$.

In this case the solution satisfies the constraint and the FOC $A_{n}=u_{3} g_{1}$. Finally, for a household with a credit opportunity,

$$
V^{2}\left(\hat{\mathbf{z}}, c_{x}\right)=\max _{c_{n}^{2}, \ell_{n}^{2}}\left\{u\left(c_{x}, c_{m}^{2}, c_{n}^{2}\right)-A_{n} \ell_{n}^{2}+\beta\left[W(\hat{\mathbf{z}})-p_{2} c_{m}^{2} \frac{A_{m}}{w^{\prime}}\right]\right\} \text { st } c_{n}^{2}=g\left(\ell_{n}^{2}, \hat{k}_{n}\right)
$$

where $p_{2}$ is the retail credit price, which generally may different from the cash price $p_{1}$. In this case the solution satisfies $u_{2}=p_{2} \beta A_{m} / w^{\prime}$ and $A_{n}=u_{3} g_{1}$. Again, naturally, different outcomes in the retail market induce different outcomes for home production.

\footnotetext{
${ }^{22}$ One can alternatively assume $\ell_{n}$ is decided before knowing the outcome in the retail market, but that seems less natural.
} 
It is now routine to derive the household's conditions generalizing (4)-(6),

$$
\begin{aligned}
& \hat{m} \quad: \frac{A_{m}}{w}=\frac{\sigma_{1} u_{2}\left(c_{x}, c_{m}^{1}, c_{n}^{1}\right)}{p_{1}}+\frac{\left(1-\sigma_{1}\right) \beta A_{m}}{w^{\prime}} \\
& \hat{b} \quad: \quad \frac{p_{b} A_{m}}{w}=\frac{\beta A_{m}}{w^{\prime}} \\
& k_{m}: \frac{p_{x} A_{m}}{w}=\frac{\beta\left[r^{\prime}+\left(1-\delta_{m}\right) p_{x}^{\prime}\right] A_{m}}{w^{\prime}} \\
& k_{s}: \frac{p_{x} A_{m}}{w}=h_{1}\left(\hat{k}_{s}, \hat{k}_{l}\right) \mathbb{E} u_{2} g_{2}+\frac{\beta\left(1-\delta_{s}\right) p_{x}^{\prime} A_{m}}{w^{\prime}} \\
& k_{l}: \frac{p_{l} A_{m}}{w}=h_{2}\left(\hat{k}_{s}, \hat{k}_{l}\right) \mathbb{E}\left(u_{2} g_{2}\right)+\frac{\beta p_{l}^{\prime} A_{m}}{w^{\prime}} \\
& c_{x}: \quad \frac{p_{x} A_{m}}{w}=\mathbb{E} u_{1},
\end{aligned}
$$

where $\mathbb{E} u_{1}=\Sigma_{j} \sigma_{j} u_{1}\left(c_{x}, c_{m}^{j}, c_{n}^{j}\right)$ and $\mathbb{E} u_{2} g_{2}=\Sigma_{j} \sigma_{j} u_{3}\left(c_{x}, c_{m}^{j}, c_{n}^{j}\right) g_{2}\left(\ell_{n}^{j}, k_{n}\right)$. Retailers again purchase $x$ and convert it one-for-one into second-subperiod goods, but now they sell it for cash with probability $\sigma_{1} / n$ and for credit with probability $\sigma_{2} / n$. Given unsold inventories fully depreciate $c_{m}^{1}=c_{m}^{2}=x$, so the quantity is the same in cash and credit transactions, but the price is not. Generalizing (3), we have

$$
p_{x}=\frac{\sigma_{1} p_{1}+\sigma_{2} p_{2}}{n(1+i)}
$$

Retailers are happy to bring any inventory $x$ to the market when (22) holds.

As in the simple models, the price vector $\mathbf{p}=\left(w, r, p_{x}, p_{l}, p_{b}, p_{1}, p_{2}\right)$ can be expressed in terms of the allocation. For factor prices, $w=p_{x} f_{1}\left(\bar{\ell}_{m}, k_{m}\right)$ and $r=p_{x} f_{1}\left(\bar{\ell}_{m}, k_{m}\right)$. For land, (20) implies it is priced by its capitalized value as an input to housing, which is itself an input to home production,

$$
p_{l}=\frac{h_{2}\left(k_{s}, k_{l}\right) \mathbb{E}\left(u_{2} g_{2}\right) w}{(1-\beta) A_{m}}
$$

Notice on the RHS dividing by $A_{m}$ and multiplying by $w$ converts utils into time and time into money. For cash retail purchases we have $p_{1} c_{m}^{1}=\hat{m}=(1+\mu) M$, and for credit retail purchases $u_{2}\left(c_{x}, c_{m}^{2}, c_{n}^{2}\right)=p_{2} \beta A_{m} / w^{\prime}$. Hence, $p_{1}=(1+\mu) M / c_{m}^{1}$ 
and $p_{2}=(1+i) u_{2}\left(c_{x}, c_{m}^{2}, c_{n}^{2}\right) w / A_{m}$. Finally, (22) delivers the nominal price level.

This determines $\mathbf{p}$ as a function of the allocation. We now pare down the description of an allocation. In terms of land, structures and housing, since $k_{l}=K_{l}$ and $k_{n}=h\left(k_{s}, K_{l}\right)$, we need only keep track of $k_{n}$. In terms of consumption, we have $c_{m}^{0}=0, c_{m}^{1}=c_{m}^{2}=x$ and $c_{n}^{j}=g\left[\ell_{n}^{j}, h\left(k_{s}, 1\right)\right]$. Therefore, we can fully describe an allocation by purchases of first-subperiod goods by households and retailers, market and home capital, and market and home work, say $\mathbf{a}=\left(c_{x}, x, k_{m}, k_{n}, \bar{\ell}_{m}, \ell_{n}^{j}\right)$.

Formally, we have the following:

Definition 1 A steady state equilibrium is an allocation and price vector $(\mathbf{a}, \mathbf{p})$ satisfying: the FOC's for home work

$$
A_{n}=u_{3}\left[c_{x}, c_{m}^{j}, g\left(\ell_{n}^{j}, k_{n}\right)\right] g_{1}\left(\ell_{n}^{j}, k_{n}\right),
$$

where it is understood that $c_{m}^{0}=0$ and $c_{m}^{1}=c_{m}^{2}=x$; steady state versions of the investment Euler Equations (18)-(19)

$$
\begin{aligned}
\rho+\delta_{m} & =f_{2}\left(\bar{\ell}_{m}, k_{m}\right) \\
\rho+\delta_{s} & =f_{1}\left(\bar{\ell}_{m}, k_{m}\right) h_{1}\left(k_{s}, 1\right)(1+\rho) \mathbb{E} u_{2} \frac{g_{2}}{A_{m}}
\end{aligned}
$$

the money Euler Equation (16), which we rewrite as

$$
A_{m}\left(\sigma_{1}+i\right)=(1+i) \sigma_{1} u_{2}\left(c_{x}, x, c_{n}^{1}\right) \frac{w}{p_{1}}
$$

the FOC for $c_{x}$ and aggregate feasibility

$$
\begin{aligned}
A_{m} & =f_{1}\left(\bar{\ell}_{m}, k_{m}\right) \mathbb{E} u_{1} \\
f\left(\bar{\ell}_{m}, k_{m}\right) & =c_{x}+n x+\delta_{k} k_{m}+\delta_{s} k_{s}^{\prime} ;
\end{aligned}
$$

and prices, which are determined as discussed above. 
Given (a, p), other objects of interest are easily computed. The average retail price and markup are

$$
p_{c}=\frac{\sigma_{1} p_{1}+\sigma_{2} p_{2}}{\sigma_{1}+\sigma_{2}} \text { and } \frac{p_{c}}{p_{x}}=\frac{n(1+i)}{\sigma_{1}+\sigma_{2}} .
$$

Real GDP is

$$
y=\left(\sigma_{1} p_{1}+\sigma_{2} p_{2}\right) x / p_{x}+\left(\delta_{m} k_{m}+\delta_{s} k_{s}+c_{x}\right)
$$

Velocity is $v=p_{x} y / M$, and a standard notion of money demand (see, e.g., Lucas 2000) is $1 / v=M / p_{x} y$. Finally, consider $p_{n}$ and $p_{n} k_{n}$. To help with the accounting, we introduce competitive home builders, who combine land and structures to deliver $k_{n}=h\left(k_{s}, k_{l}\right)$. Profit from this activity is $p_{n} h\left(k_{s}, k_{l}\right)-p_{x} k_{s}-p_{l} k_{l}=0$. Therefore, in equilibrium, $p_{n} k_{n}=p_{x} k_{s}+p_{l} k_{l}$ and $p_{n}=\left(p_{x} k_{s}+p_{l} k_{l}\right) / h\left(k_{s}, k_{l}\right)$.

\section{Quantitative Results}

We use standard technologies: $f\left(\ell_{m}, k_{m}\right)=\ell_{m}^{\chi_{m}} k_{m}^{1-\chi_{m}}, g\left(\ell_{n}, k_{n}\right)=\ell_{n}^{\chi_{n}} k_{n}^{1-\chi_{n}}$ and $h\left(k_{s}, k_{l}\right)=k_{s}^{\chi_{h}} k_{l}^{1-\chi_{h}}$. For preferences, as there are three goods, we consider two specifications. In Calibration $1, c_{x}$ and $c_{m}$ are perfect substitutes and we identify them collectively as market consumption,

$$
u\left(c_{x}, c_{m}, c_{n}\right)=\log \left[\left(c_{m}+B c_{x}\right)^{\omega}+c_{n}^{\omega}\right]^{\frac{1}{\omega}}
$$

And important object in the calibration is the ES (elasticity of substitution) between market and home goods, which for this specification in simply $1 /(1-\omega)$. In Calibration 2, we use

$$
u\left(c_{x}, c_{m}, c_{n}\right)=B \log \left(c_{x}\right)+(1 / \omega) \log \left(c_{m}^{\omega}+c_{n}^{\omega}\right)
$$

Here $\omega$ no longer directly captures the ES we want to target, so we average using expenditure shares the ES between $c_{x}$ and $c_{n}$. 
We use long-run observations to calibrate parameters when we can. Then, as is standard in monetary models, we use properties of the empirical money demand curve for some others, since for our experiments it is important that the model line up well with standard monetary observations. Unless otherwise noted, our targets are computed using U.S. data from 1975 to 1999, since we are not attempting to explain the housing bubble. The length of a period is a quarter. The average annual inflation and T-bill rates are $4.13 \%$ and $6.80 \%$ in the sample, which yield $\rho=0.0066$ and $\mu=0.0103$. We set $\chi_{h}=0.73$ to match the value of residential structures plus durables relative to the value of housing capital. Then, to match the investment flows over the capital stocks for both $k_{m}$ and $k_{s}$ we set $\delta_{m}=\delta_{s}=0.015$, which translates to $6 \%$ annual depreciation rates (it is a coincidence that they are the same). We set $\sigma_{2}=0.5 \sigma_{1}$ so that there are half as many retail trades made on credit as there are in money, based on the data in the recent Bank of Canada Methods of Payment Survey. ${ }^{23}$

A key element in any model with home production is the ES between market and home goods. Benhabib et al. (1991) argue for an ES of 5, but in retrospect that was probably too high. Estimates by Rupert et al. (1995) using PSID data yield numbers closer to 1.8 or 2. Estimates by McGrattan et al. (1997) using aggregate time series yield values between 1.5 and 1.8. Aguiar and Hurst (2007a) estimate an ES of 1.8 from time-use data, while Chang and Schorfheide (2003) get a slightly higher 2.3. While there is no single definitive number emerging from these papers, there seems to be a consensus on a reasonable range. We pick an ES of 1.8. In Calibration 1 this immediately implies $\omega=0.44$, while in Calibration 2 we need to set $\omega$ together with the remaining parameters to match the targets jointly.

\footnotetext{
${ }^{23}$ As described in Arango and Welte (2012), the probabilities of using cash in any transaction for single and married people are $55 \%$ and $48 \%$, resp., and the probabilities of using credit cards are $20 \%$ and $25 \%$, resp., making $\sigma_{2}$ close to $\sigma_{1} / 2$.
} 
At this point, for Calibration 1 the parameters $\left(A_{m}, A_{n}, B, \chi_{m}, \chi_{n}, n, \sigma_{1}\right)$, and for Calibration 2 these plus $\omega$, are calibrated to match the following targets. As is standard (Greenwood et al. 1995) households spend on average $\bar{\ell}_{m}=33 \%$ of their discretionary time working in the market and $\bar{\ell}_{n}=25 \%$ working in the home, while market capital over annual output is $k_{m} / y=2.07$ and household capital over annual output is $k_{n} / y=1.96$. For the retail markup, we target $30 \%$ based on data from the Annual Retail Trade Survey, following Faig and Jerez (2005). Finally, we match the level and slope of money demand, targeting an average annual velocity of 5.76 and a semi-elasticity with respect to $i$ of $2.56 \%$, obtained using a standard log-linear regression. While the parameters are calibrated jointly, heuristically $A_{m}$ and $A_{n}$ match the hours targets, $\chi_{m}$ and $\chi_{n}$ match the capital-output ratios, $n$ matches the markup, $B$ matches the level of velocity and $\sigma_{1}$ matches the money-demand elasticity. ${ }^{24}$

The top panel of Table 2 reports the calibration results. In Calibration $2 \omega$ is 0.83, which implies a large ES between $c_{m}$ and $c_{n}$, but maintains the target ES between overall market and nonmarket goods of 1.8. In terms of the retail market, consider Calibration 1 (the other is similar). The measure of retailers is $n=0.22$, and the measure of households that trade each period is $\sigma_{1}+\sigma_{2}=0.17$. Also, $\left(\sigma_{1}+\sigma_{2}\right) / n$, or $78 \%$, is the fraction of retail inventories sold each period, while the rest simply depreciate. About $15 \%$ of market consumption comes from retail, $c_{m}$; the rest, $c_{x}$, is purchased directly from producers in the first subperiod. These numbers are largely driven by the average velocity target, which cannot be matched well without $c_{x}$ in the model. To understand the importance of home production, we compute the percentage increase in market consumption required to compensate for the loss if we force $c_{n}=\ell_{n}=0$. For households that are able to trade in the retail

\footnotetext{
${ }^{24}$ Since the calibrations match the targets virtually exactly - i.e., up to many decimal points we do not provide tables with targets and model-implied moments.
} 
market, each period market consumption has to increase by $78 \%$ to compensate for shutting down home production. For households that cannot trade in the retail market, the number is $152 \%$. Based on these observations, it is clear that it is important to have all three goods, $\left(c_{x}, c_{m}, c_{n}\right)$, in the specification.

\subsection{Positive Results}

We now ask how well the model accounts for the relationship discussed in Section 2 between nominal interest rates, on the one hand, and the value of home capital over nominal output or over the money supply, on the other. Denote the value of home capital over nominal output and over the money supply by $H / Y$ and $H / M$. These ratios are tightly connected to inverse velocity, $Y / M$, by the relationship $H / M=$ $H / Y \times Y / M$. Since the average value of $H / Y$ and $Y / M$ are calibration targets, the average value of $H / M$ matches the data, by construction. The only elasticity we target is the semi-elasticity of $Y / M$ with respect to the nominal rate, denoted $\xi_{Y / M}$. The model generates endogenously a semi-elasticity for $H / Y$, denoted $\xi_{H / Y}$, and the elasticity of $H / M$ then follows from $\xi_{H / M}=\xi_{H / Y}+\xi_{Y / M}$. While we report both, we think it more interesting to focus on $\xi_{H / Y}$ rather than $\xi_{H / M}$, for the following reason: Even if $p_{n} k_{n}$ does not move at all, as long as real balances fall with $i$, we are bound to get $\xi_{H / M}$ more or less right. It therefore seems more challenging - or, less less mechanical - to focus on $\xi_{H / Y} \cdot{ }^{25}$

Table 2 reports the results and Figure 4 shows $Y / M, H / Y$ and $H / M$ versus $i$ for Calibrations 1 and 2 as well as the data. In Calibration 1 we get $\xi_{H / Y}=0.25$ and in Calibration 2 we get $\xi_{H / Y}=0.57$, or $22 \%$ and $52 \%$ of the semi-elasticities in the data. When we consider $\xi_{H / M}$, the model accounts between $78 \%$ and $87 \%$ of the elasticity in the data, but again we prefer to focus on $\xi_{H / Y}$. Whether we

\footnotetext{
${ }^{25}$ We compute a model-based semi-elasticity as the semi-elasticity at the calibrated steady state using numerical derivatives.
} 
consider $\xi_{H / Y}$ or $\xi_{H / M}$, it matters whether we use Calibration 1 or 2 - different ways a disaggregating consumption are not equivalent, even if they hit the same ES target. In any case, Figure 4 shows how the model tracks the broad patterns in the data fairly well.

On the suggestion of the referees, we tried to establish some independent evidence for a theory that says higher inflation makes households substitute away from market and into home production. First consider time allocation. Data imply semielasticities of -0.6 and 0.2 for market and home labor, with respect to the nominal interest rate. ${ }^{26}$ This is very much in line with the predictions of the theory, although the corresponding numbers from the calibrated model are smaller, -0.2 and 0.04 . Still, this supports the general approach. In terms of consumption, there is no long time series of home production, but we can present some corroborating evidence. Take the ratio of "food and beverages purchased for off-premises consumption" and "purchased meals and beverages," where the former is an input to home production and the latter is market consumption. Theory suggests this ratio should go up with inflation. The interest semi-elasticity of this ratio is $0.4 .^{27}$ This also supports the general approach.

Table 3 shows the findings are quite robust (in each case changing the calibration as appropriate). Changing risk aversion from 1 to $1 / 2$ or 2 has little effect. The same is true for increasing the calibration frequency to monthly or even weekly. This is important because it is one of the reasons for modeling retail as a frictional market. With a typical cash-in-advance model, e.g., households spend all their money each period, so there is no way to match velocity when the period length is short. Here we

\footnotetext{
${ }^{26}$ For market labor we use hours-worked by prime-aged men between 1955-2005 from Francis and Ramey (2009). For time spent in home production we use data from Ramey (2009) for employed males between 1975-2003. Both of these series contain significant trends that we removed linearly.

${ }^{27}$ This data covers the period 1955-2005, from Table 2.4.5 of the BEA, and in this case we removed a cubic trend.
} 
can shorten the period and keep everything basically the same by scaling the arrival rates $\sigma_{j}$. In terms of the basic structure, one modification we consider is setting $\chi_{h}=0$ and thus removing home labor from the model. This only slightly weakens the main result $-\xi_{H / Y}$ goes down from 0.25 to 0.19. As regards the ES target, varying this in the range 1.5 to 2.3 yields roughly similar results. In Calibration 2, if we use an ES of 5 , we can account for $100 \%$ of $\xi_{H / Y}-$ but 5 is too high given the empirical consensus. We prefer to conclude conservatively that the model accounts for between $20 \%$ and $50 \%$ of the $\xi_{H / Y}$ relationship, which is clearly relevant, but also leaves room for other factors.

\subsection{Normative Results}

We are also interested in the welfare effects of inflation. A standard exercise is to compute the cost of inflation as the amount of consumption households would be willing to sacrifice to go from $10 \%$ to the Friedman rule, which means an inflation rate consistent with a 0 nominal interest rate. A consensus estimate from reducedform analyses is that the answer is between $0.5 \%$ and $1.0 \%$. By comparison, in models along the lines of Lagos and Wright (2005), the number can be an order of magnitude higher. One reason for the big effects in those models is that they use bargaining rather competitive pricing. Since it is well known that bargaining matters, we instead consider the change in welfare effects that come from adding home production keeping pricing the same. ${ }^{28}$

Figure 5 shows how equilibrium changes with inflation for the two benchmark calibrations, as well as a version of the model with home production shut down. Since inflation is a tax on money holdings, higher inflation reduces real balances, and hence

\footnotetext{
${ }^{28}$ See Aruoba et al. (2011) for a recent paper with references to work on the cost of inflation. including price-taking and bargaining models. Note also that bargaining power is usually calibrated to match the markup in those models, but we get positive markups in the retail market even with competitive pricing due to the other frictions.
} 
the demand by retailers for inventories, and hence employment and investment. In the model without home production, market activity falls with inflation, and this creates a loss in welfare. In the model with home production, agents can make up for some of the loss in $c_{m}$ by increasing $c_{n}$. However, on net the cost of inflation is larger when home production is an option: going from $10 \%$ inflation to the Friedman rule implies a welfare gain of $0.4 \%$ without home production, $0.53 \%$ in Calibration 1, and $0.65 \%$ in Calibration 2. We conclude that incorporating home production raises the cost of inflation by somewhere between $1 / 3$ and $2 / 3$.

Again, an individual's response to an increase in inflation is to reduce market and increase nonmarket activity. Depending on the how willing the individual is to substitute between $c_{m}$ and $c_{n}$, individual welfare may be minimally affected by this. However, relative to the no-home-production version, the ratio of $c_{m}$ to total consumption spending is larger in the model with home production. This makes a decrease in $c_{m}$ due to an increase in inflation more costly and since they are only imperfect substitutes, the increase in $c_{n}$ does not completely make up for the loss in $c_{m}$. In summary, for the cost of inflation, home production makes a difference. While there is room for more work on the issue, it looks like the microfoundations of household behavior matter, just like the microfoundations of monetary exchange matter, for quantitative policy questions.

\section{Conclusion}

This paper reports our research on integrating models with money, home production, and the production of homes. This is natural to the extent that monetary policy provides incentives for agents to reallocate labor and capital between market and household activity. In the data, we found that appropriately-scaled values of housing wealth rise with inflation or nominal interest rates. Theory generates analytic pre- 
dictions that are qualitatively consistent with this. Our quantitative work showed that calibrated models can account for some but not all of the observations. While this leaves is room for other factors, the channel we highlight is clearly relevant. To repeat what we said regarding the cost of inflation, the results suggest strongly that the microfoundations of household behavior matter, just like the microfoundations of monetary economics matter, for monetary policy issues. That this not universally understood or accepted is evidenced by the fact that many models used for policy analysis these days pay little or no attention to these microfoundations. We hope our results encourage at least some people to further pursue more detailed models of monetary exchange and household behavior.

\section{References}

[1] Aguiar, M. and E. Hurst, 2005, "Consumption versus Expenditure," Journal of Political Economy 113, 919-48.

[2] Aguiar, M. and E. Hurst, 2007a, "Life-Cycle Prices and Production," American Economic Review 97, 1533-59.

[3] Aguiar, M. and E. Hurst, 2007b, "Measuring Trends in Leisure: The Allocation of Time over Five Decades," Quarterly Journal of Economics 122, 969-1006.

[4] Arango, C. and A. Welte, 2012, "The Bank of Canada's 2009 Methods of Payment Survey: Methodology and Key Results," Bank of Canada Working Paper.

[5] Albanesi, S. and C. Olivetti, 2009, "Home Production, Market Production and the Gender Wage Gap: Incentives and Expectations," Review of Economic Dynamics 12, 80-107.

[6] Albrecht, J., A. Anderson, E. Smith and S. Vroman, 2007, "Opportunistic Matching In The Housing Market," International Economic Review 48, 64164 .

[7] Andre, C., 2010, "A Bird's Eye View of OECD Housing Markets," OECD Economics Department Working Paper 746.

[8] Aruoba, S.B., C.J. Waller and R. Wright, 2011, "Money and Capital," Journal of Monetary Economics 58, 98-116. 
[9] Baxter, M. and U.J. Jermann, 1999, "Household Production and the Excess Sensitivity of Consumption to Current Income," American Economic Review 89, 902-20.

[10] Baxter, M., 2010, "Detecting Household Production," manuscript, BU.

[11] Berentsen, A., G. Menzio and R. Wright, 2011, "Inflation and Unemployment in the Long Run," American Economic Review 101, 371-398

[12] Becker, G.S., 1965, "A Theory of the Allocation of Time," Economic Journal 75, 493-508.

[13] Becker, G.S., 1988, "Family Economics and Macro Behavior," American Economic Review 78, 1-13.

[14] Benhabib, J., R. Rogerson and R. Wright, 1991, "Homework in Macroeconomics: Household Production and Aggregate Fluctuations," Journal of Political Economy 99, 1166-1187.

[15] Brunnermeier, M.K. and C. Julliard, 2008, "Money Illusion and Housing Frenzies," Review of Financial Studies 21, 135-80.

[16] Burnside, M. Eichenbaum and S. Rebelo, 2011, "Understanding Booms and Busts in Housing Markets," manuscript.

[17] Caplin, A. and J. Leahy, 2008, "Trading Frictions and House Price Dynamics," manuscript, NYU.

[18] Chang, Y. and F. Schorfheide, 2003, "Labor-Supply Shifts and Economic Fluctuations," Journal of Monetary Economics 50, 1751-1768.

[19] Chiu, J. and M. Molico, 2010, "Liquidity, Redistribution, and the Welfare Cost of Inflation," Journal of Monetary Economics 57, 428-438.

[20] Chiu, J. and M. Molico, 2011, "Uncertainty, Inflation, and Welfare," Journal of Money, Credit and Banking 43, 487-512.

[21] Coulson, N.E. and L.M. Fisher, 2009, "Housing Tenure and Labor Market Impacts: The Search Goes On," Journal of Urban Economics 65, 252-64.

[22] Christiano, L.J., M. Eichenbaum and C.L. Evans, 2005, "Nominal Rigidities and the Dynamic Effects of a Shock to Monetary Policy," Journal of Political Economy 113, 1-45.

[23] Cynamon, B.Z., D.H. Dutkowsky and B.E. Jones, 2006, "Redefining the Monetary Agggregates: A Clean Sweep," Eastern Economic Journal 32, 661-72. 
[24] Davis, M.A., J.D.M. Fisher and T.M. Whited, 2014, "Macroeconomic Implications of Agglomeration," Econometrica, forthcoming.

[25] Davis, M.A. and J. Heathcote, 2005, "Housing And The Business Cycle," International Economic Review 46, 751-84.

[26] Davis, M.A. and J. Heathcote, 2007, "The Price and Quantity of Land in the United States," Journal of Monetary Economics 54, 2595-620.

[27] Dressler, S.J., 2011, "Money Holdings, Inflation, and Welfare in a Competitive Market," International Economic Review 52, 407-423.

[28] Einarsson, T. and M.H. Marquis, 1997, "Home Production with Endogenous Growth," Journal of Monetary Economics 39, 551-69.

[29] Faig, M. and B. Jerez, 2005, "A Theory of Commerce," Journal of Economic Theory 122, 60-99.

[30] Ferguson, N., 2008, The Ascent of Money: A Financial History of the World. Penguin Press HC.

[31] Fisher, J., 1997, "Relative Prices, Complementarities and Comovement among Components of Aggregate Expenditures," Journal of Monetary Economics 39, 449-74.

[32] Fisher, J., 2007, "Why Does Household Investment Lead Business Investment over the Business Cycle?" Journal of Political Economy 115, 141-68.

[33] Follain, J.R., 1982, "Does Inflation Affect Real Behavior: The Case of Housing," Southern Economic Journal 48, 570-82.

[34] Geromichalos, A., J.M. Licari and J. Suarez-Lledo, 2007, "Asset Prices and Monetary Policy," Review of Economic Dynamics 10, 761-79.

[35] Gomme, P., F. Kydland and P. Rupert, 2001, "Home Production Meets Time to Build," Journal of Political Economy 109, 1115-31.

[36] Gomme, P., P. Rupert, R. Rogerson and R. Wright, 2004, "The Business Cycle and the Life Cycle," NBER Macroeconomics Annual 19.

[37] Greenwood, J. and Z. Hercowicz, 1991, "The Allocation of Capital and Time over the Business Cycle," Journal of Political Economy 99, 1188-214.

[38] Greenwood, J., R. Rogerson and R. Wright, 1995, "Household Production in Real Business Cycle Theory," in Frontiers of Business Cycle Theory, ed. T. Cooley, Princeton. 
[39] Greenwood, J., A. Seshadri and M. Yorukoglu, 2005, "Engines of Liberation," Review of Economic Studies 72, 109-33.

[40] Gronau, R., 1997, "The Theory of Home Production: The Past Ten Years," Journal of Labor Economics 15, 197-205.

[41] He, C., R. Wright and Y. Zu, 2011, "Housing and Liquidity," manuscript.

[42] Head, A. and H. Lloyd-Ellis, 2012, "Housing Liquidity, Mobility and the Labour Market," Review of Economic Studies, forthcoming.

[43] Holmstrom, B. and J. Tirole, 2011,. Inside and Outside Liquidity. MIT Press.

[44] House, C., J. Laitner and D. Stolyarov, 2008, "Valuing Lost Home Production Of Dual Earner Couples," International Economic Review 49, 701-36.

[45] Kearl, J.R., 1979, "Inflation, Mortgages, and Housing," Journal of Political Economy 87, 1115-38.

[46] Kydland, F.E. and E.C. Prescott, 1982, "Time to Build and Aggregate Fluctuations," Econometrica 50, 1345-1370.

[47] Lagos, R. and R. Wright, 2005 "A Unified Framework for Monetary Theory and Policy Analysis" Journal of Political Economy 113, 463-84.

[48] Lester, B., A. Postlewaite and R. Wright, 2012, "Liquidity, Information, Asset Prices and Monetary Policy," Review of Economic Studies 79, 1209-1238.

[49] Lucas, R.E., 2000, "Inflation and Welfare," Econometrica 68, 247-74.

[50] McGrattan, E.R., R. Rogerson and R. Wright, 1997, "An Equilibrium Model of the Business Cycle with Household Production and Fiscal Policy," International Economic Review 38, 267-90.

[51] Mian, A., and A. Sufi, 2011, "House Prices, Home Equity-Based Borrowing, and the US Household Leverage Crisis," American Economic Review 101, 2132-56.

[52] Ngai, L.R. and S. Tenreyro, 2009, "Hot and Cold Seasons in the Housing Market," manuscript, LSE.

[53] Ngai, L.R. and C.A. Pissarides, 2008, "Trends in Hours and Economic Growth," Review of Economic Dynamics 11, 239-56.

[54] Nosal, E., and G. Rocheteau, 2011, Money, Payments, and Liquidity, MIT Press. 
[55] Novy-Marx, R., 2009, "Hot and Cold Markets," Real Estate Economics 37, $1-22$.

[56] Parente, S., R. Rogerson and R. Wright, 2000, "Homework in Development Economics: Household Production and the Wealth of Nations," Journal of Political Economy 108, 680-7.

[57] Piazzesi, M. and M. Schneider, 2009, "Momentum Traders in the Housing Market: Survey Evidence and a Search Model," AER Papers 83 Proceedings 99, 406-11.

[58] Piazzesi, M. and M. Schneider, 2010, "Inflation and the Price of Real Assets," manuscript, Stanford.

[59] Poterba, J. M., 1991, "House Price Dynamics: The Role of Tax Policy and Demography," Brookings Papers on Economic Activity 22, 143-203.

[60] Ramey, V.A., 2009, "Time Spent in Home Production in the Twentieth-Century United States: New Estimates from Old Data," Journal of Economic History, $69,1-47$.

[61] Ramey, V.A. and N. Francis, 2009, "A Century of Work and Leisure," American Economic Journal: Macroeconomics, 1, 189-224.

[62] Ríos-Rull, J.-V., 1993, "Working in the Market, Working at Home, and the Acquisition of Skills: A General-Equilibrium Approach," American Economic Review 83, 893-907.

[63] Reinhart, C. and K. Rogoff, 2009, This Time is Different: Eight Centuries of Financial Folly. Princeton University Press.

[64] Rocheteau, G. and R. Wright, 2005, "Money in Search Equilibrium, in Competitive Equilibrium, and in Competitive Search Equilibrium," Econometrica $73,175-202$.

[65] Rogerson, R., 2009, "Market Work, Home Work, and Taxes: A Cross-Country Analysis," Review of International Economics 17, 588-601.

[66] Rogerson, R. and J. Wallenius, 2009, "Micro and Macro Elasticities in a Life Cycle Model with Taxes," Journal of Economic Theory 144, 2277-92.

[67] Rupert, P., R. Rogerson and R. Wright, 1995, "Estimating Substitution Elasticities in Household Production Models," Economic Theory 6, 179-93.

[68] Rupert, P., R. Rogerson and R. Wright, 2000, "Homework in Labor Economics: Household Production and Intertemporal Substitution," Journal of Monetary Economics 46, 557-79. 
[69] Sanches, D. and S. Williamson, 2010, "Money and Credit with Limited Commitment and Theft," Journal of Economic Theory 145, 1525-1549.

[70] Shiller, R., 2005, Irrational Exuberance, Princeton University Press.

[71] Venkateswaran, V. and R. Wright, 2013, "Pledgability and Liquidity: A New Monetarist Model of Financial and Macroeconomic Activity," NBER Macro Annual, in press.

[72] Wheaton, W.C., 1990, "Vacancy, Search, and Prices in a Housing Market Matching Model," Journal of Political Economy 98, 1270-92.

[73] Williamson, S. and R. Wright, 2010a, "New Monetarist Economics: Methods," FRB St Louis Rev. 92, 2010.

[74] Williamson, S. and R. Wright, 2010b, "New Monetarist Economics: Models," Handbook of Monetary Economics, eds. B. Friedman and M. Woodford, Elsevier.

[75] Wong, R., 2012, "A Tractable Monetary Model under General Preferences," Bank of Canada mimeo. 
Table 1: Comparison of Shiller and Decennial Census Data

\begin{tabular}{|c|c|c|c|c|}
\hline \multirow[b]{2}{*}{ Decade } & \multicolumn{4}{|c|}{ Total Percent Growth } \\
\hline & Shiller HPI & Avg. Price (DCH) & Housing Units (DCH) & Nominal GDP \\
\hline & (1) & $(2)$ & $(3)$ & $(4)$ \\
\hline $1950-1960$ & 30.1 & 45.2 & 31.1 & 74.9 \\
\hline $1960-1970$ & 28.9 & 49.1 & 24.7 & 97.8 \\
\hline $1970-1980$ & 118.3 & 188.6 & 27.3 & 166.6 \\
\hline 1980-1990 & 71.2 & 93.4 & 12.8 & 106.1 \\
\hline $1990-2000$ & 35.3 & 41.2 & 14.9 & 71.5 \\
\hline
\end{tabular}

Table 2: Quantitative Results

\begin{tabular}{|c|c|c|}
\hline & Calibration 1 & Calibration 2 \\
\hline \multicolumn{3}{|c|}{ Calibrated Parameters } \\
\hline$A_{m}$ & 1.27 & 2.14 \\
\hline$A_{n}$ & 2.08 & 3.14 \\
\hline$B$ & 0.33 & 0.59 \\
\hline$\chi_{m}$ & 0.82 & 0.82 \\
\hline$\chi_{n}$ & 0.91 & 0.90 \\
\hline$\sigma_{1}$ & 0.12 & 0.12 \\
\hline$\sigma_{2}$ & 0.06 & 0.06 \\
\hline$n$ & 0.22 & 0.24 \\
\hline$\omega$ & 0.44 & 0.83 \\
\hline \multicolumn{3}{|c|}{ Key Implications } \\
\hline$\xi_{H / Y}($ Data: $1.10 \%)$ & 0.25 & 0.57 \\
\hline$\%$ accounted for & 22 & 52 \\
\hline$\xi_{H / M}($ Data: $3.66 \%)$ & 2.81 & 3.13 \\
\hline$\%$ accounted for & 78 & 87 \\
\hline \multicolumn{3}{|c|}{ Welfare Gain of Going from $10 \%$ Inflation to FR } \\
\hline$\%$ of market cons. & 0.53 & 0.65 \\
\hline
\end{tabular}


Table 3: Robustness

\begin{tabular}{cccc}
\hline & $\xi_{H / Y}$ & $\xi_{H / M}$ & Welfare Gain \\
\hline Benchmark & 0.25 & 2.81 & 0.53 \\
Monthly & 0.21 & 2.77 & 0.48 \\
Weekly & 0.17 & 2.73 & 0.42 \\
No Home Labor & 0.19 & 2.75 & 0.42 \\
$\sigma=2$ & 0.18 & 2.74 & 0.40 \\
$\sigma=0.5$ & 0.31 & 2.87 & 0.71 \\
\hline
\end{tabular}


Figure 1: DH-Based Home Capital
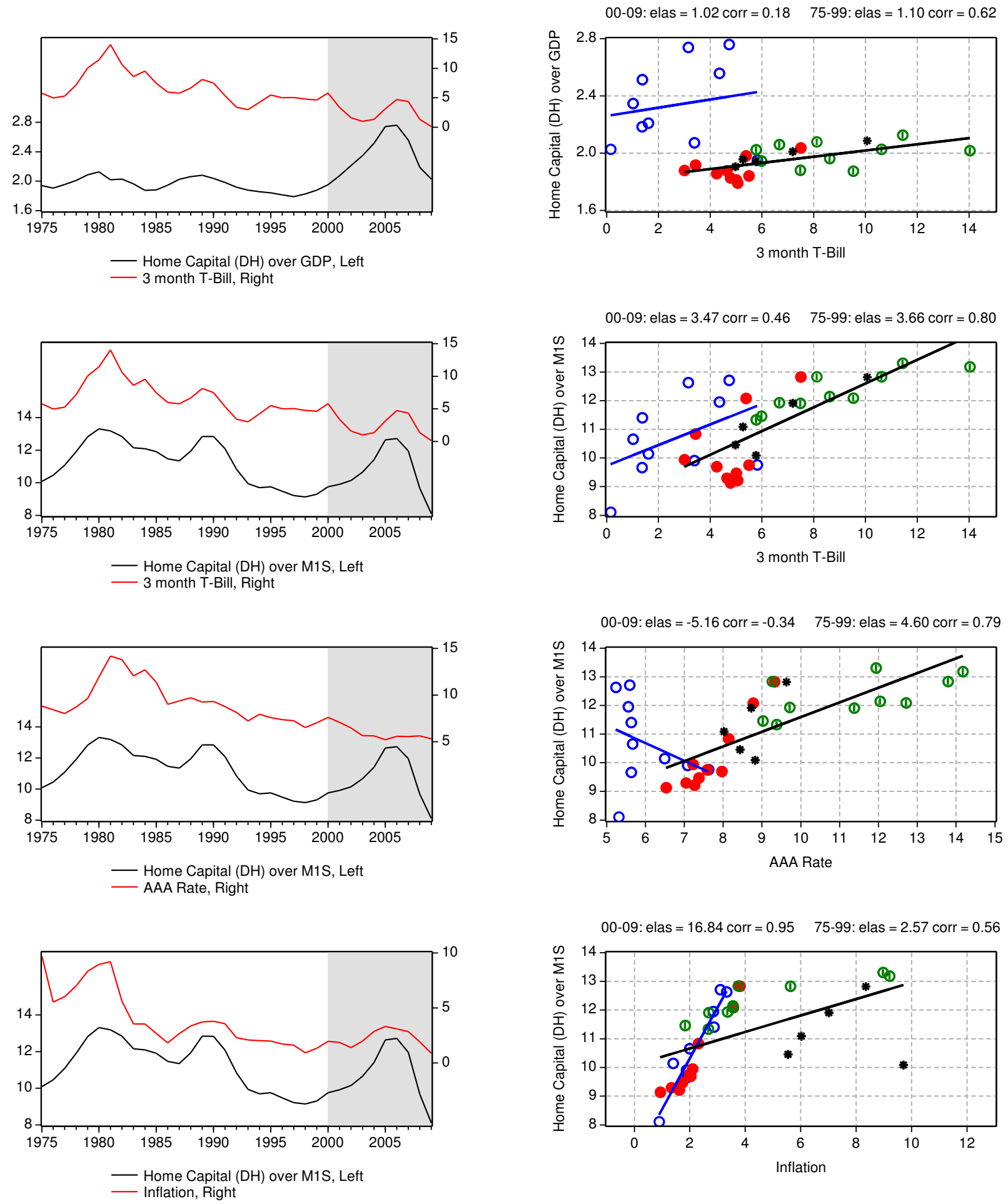

blue 00-09; red 90-99; green 80-89; black 75-79 


\section{Figure 2: Other Measures of Home Capital}
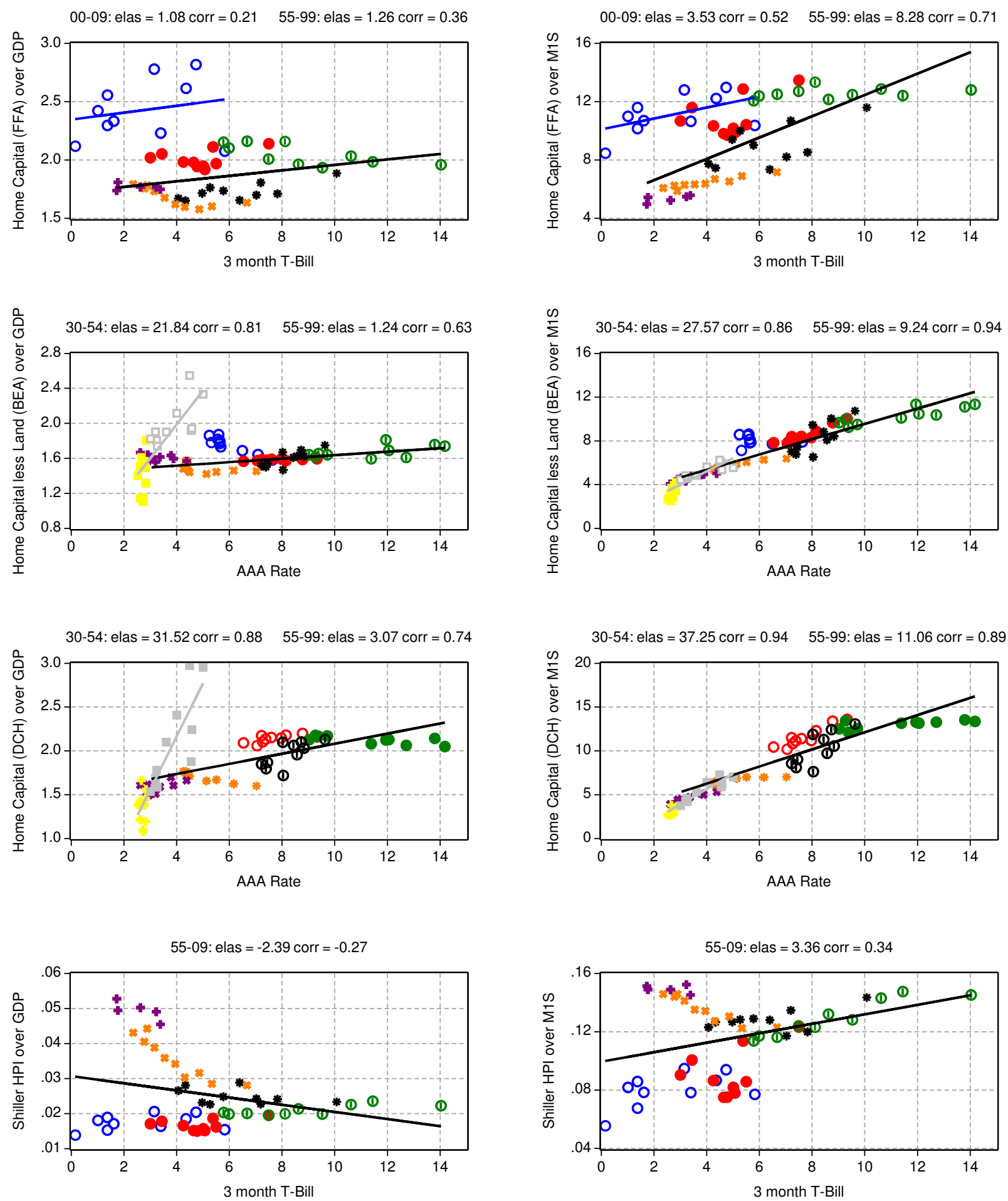

blue 00-09; red 90-99; green 80-89; black 70-79; orange 60-69; purple 50-59; yellow 40-49; gray 30-39 
Figure 3: International HPI

( $y$ axis is value of HPI and $x$ axis is rate of inflation)

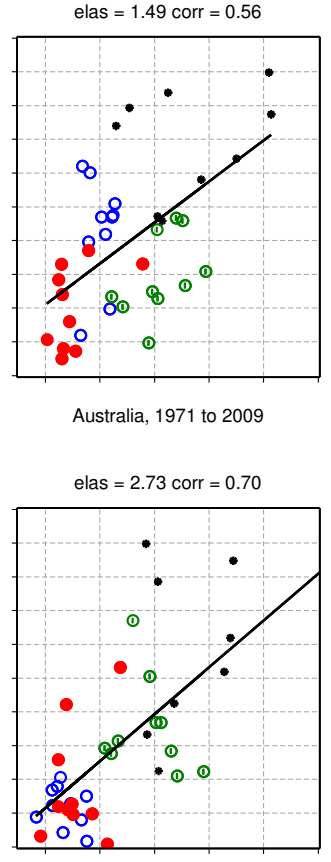

Finland, 1971 to 2009

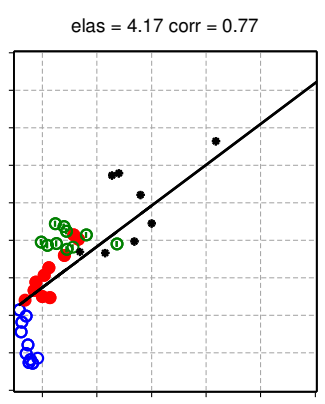

Japan, 1971 to 2009

elas $=-0.88$ corr $=-0.30$

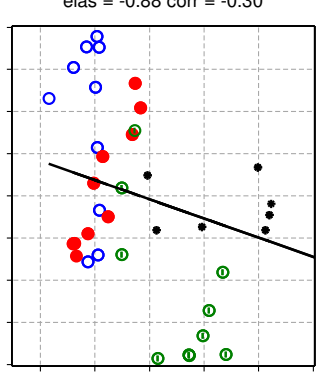

Spain, 1971 to 2009 elas $=-1.28$ corr $=-0.21$

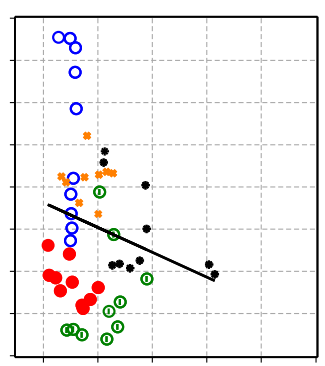

Belgium, 1961 to 2009

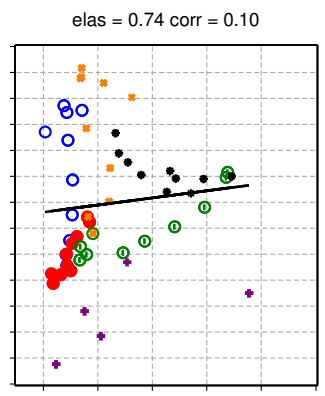

France, 1955 to 2009

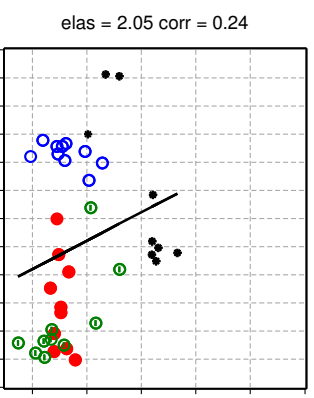

Netherlands, 1971 to 2009

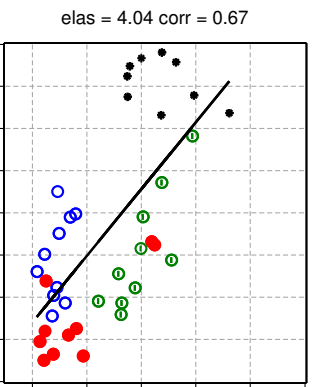

Sweden, 1971 to 2009 elas $=2.29$ corr $=0.63$

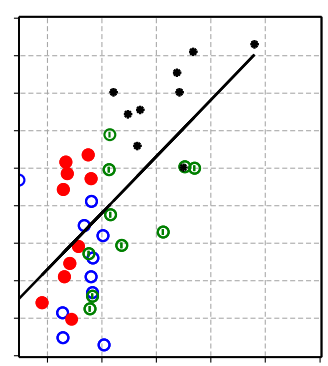

Canada, 1971 to 2009

elas $=2.91$ corr $=0.68$

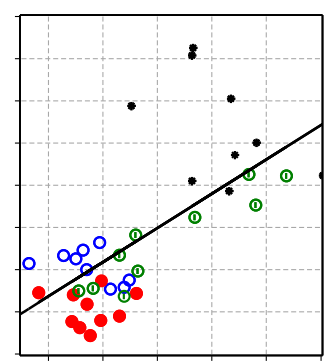

Ireland, 1970 to 2009

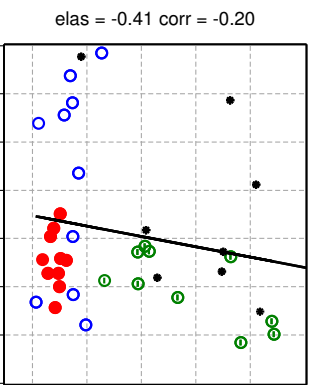

New Zealand, 1971 to 2009

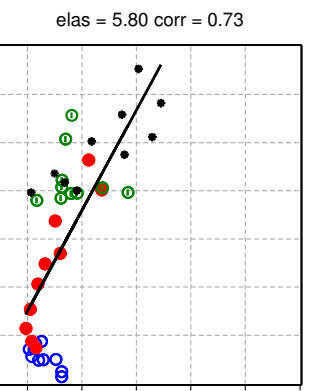

Switzerland, 1970 to 2009

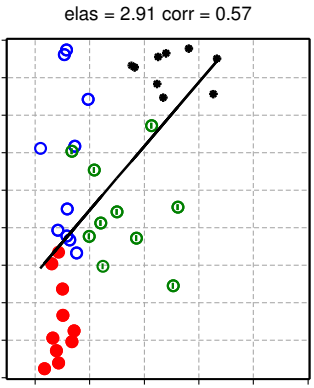

Denmark, 1971 to 2009

elas $=2.23$ corr $=0.79$

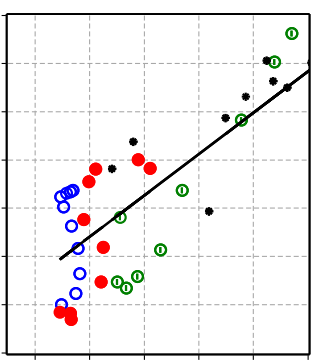

Italy, 1971 to 2009

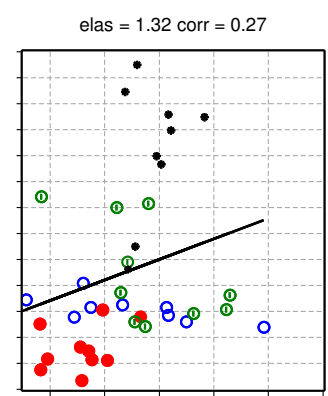

Norway, 1971 to 2009

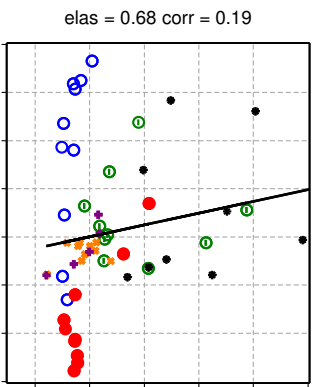

UK, 1955 to 2009

blue 00-09; red 90-99; green 80-89; black 70-79; orange 60-69; purple 50-59; 
Figure 4: Results from the Model - Key Objects
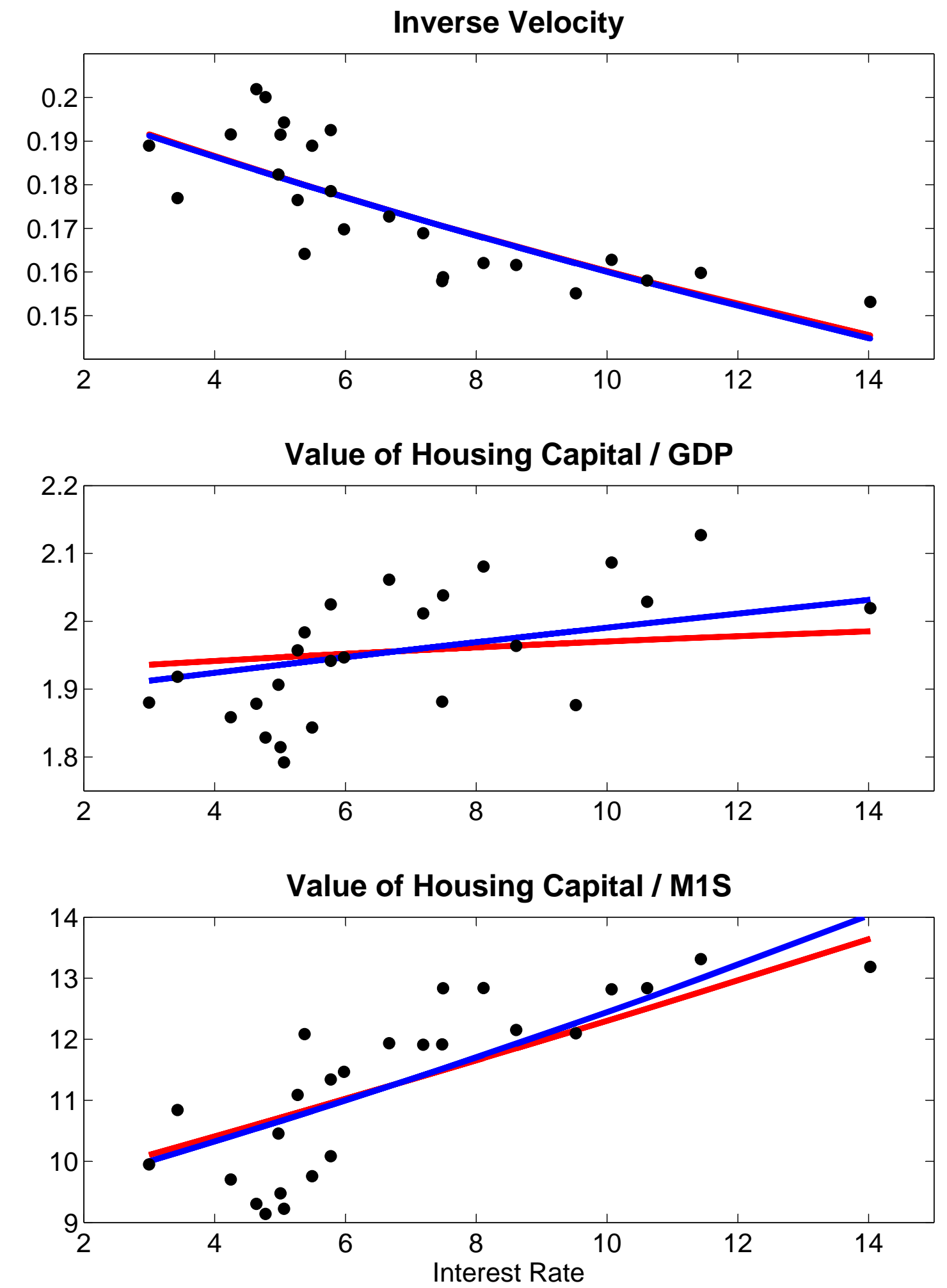

Notes: Red line: calibration 1, blue line: calibration 2, black: data. 
Figure 5: Results from the Model - Effect of Inflation
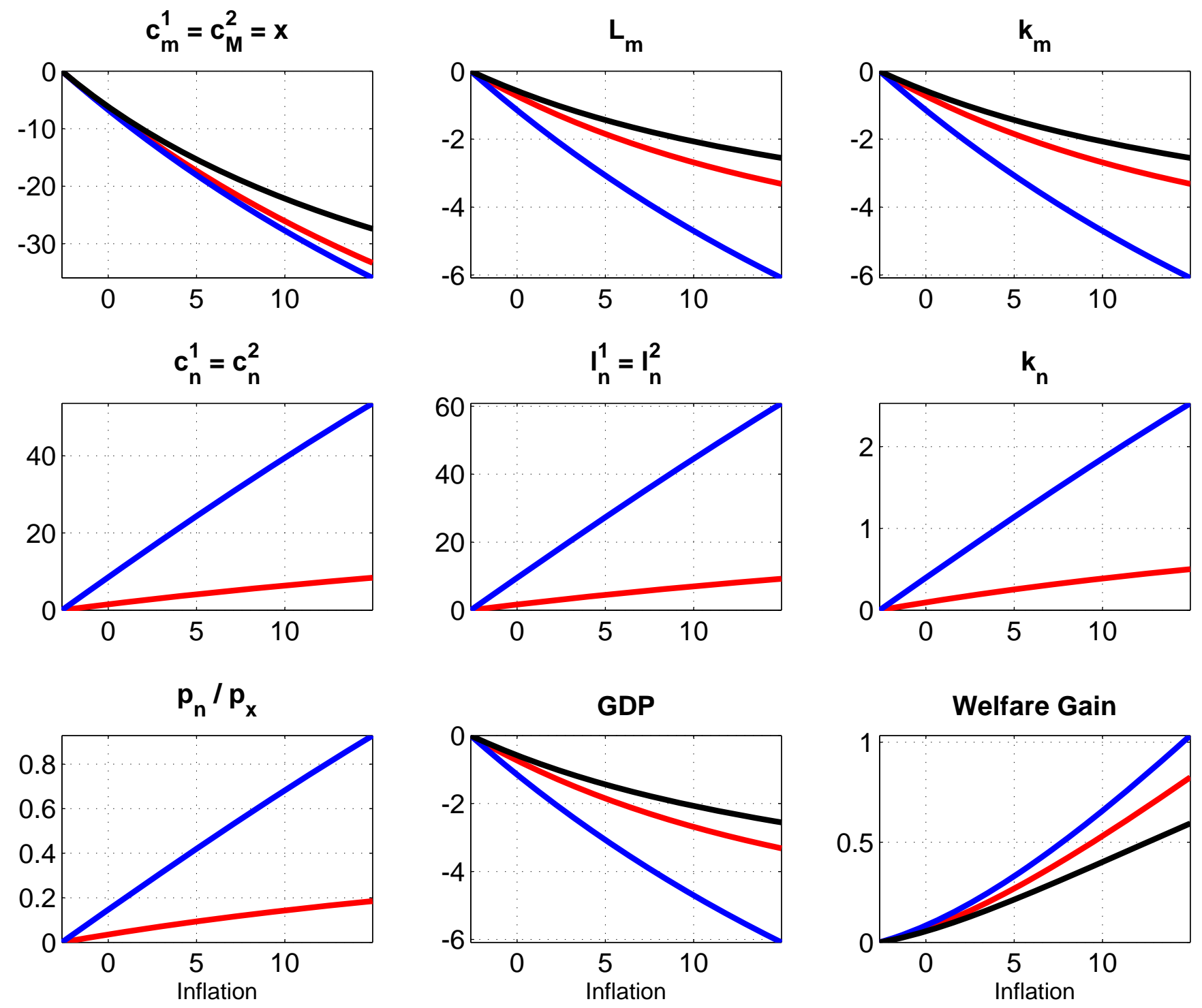

Notes: Red: Calibration 1, blue: Calibration 2, black: no home production. All quantities are relative to the value for $0 \%$ interest rate, expressed in percentage units except for welfare which shows the welfare gain of reducing the interest rate from the shown level to $0 \%$, expressed in percentage of consumption. 